\title{
Studies in Conservation
}

\section{Consolidation and chromatic reintegration of historical renders with lime-based pozzolanic products \\ --Manuscript Draft--}

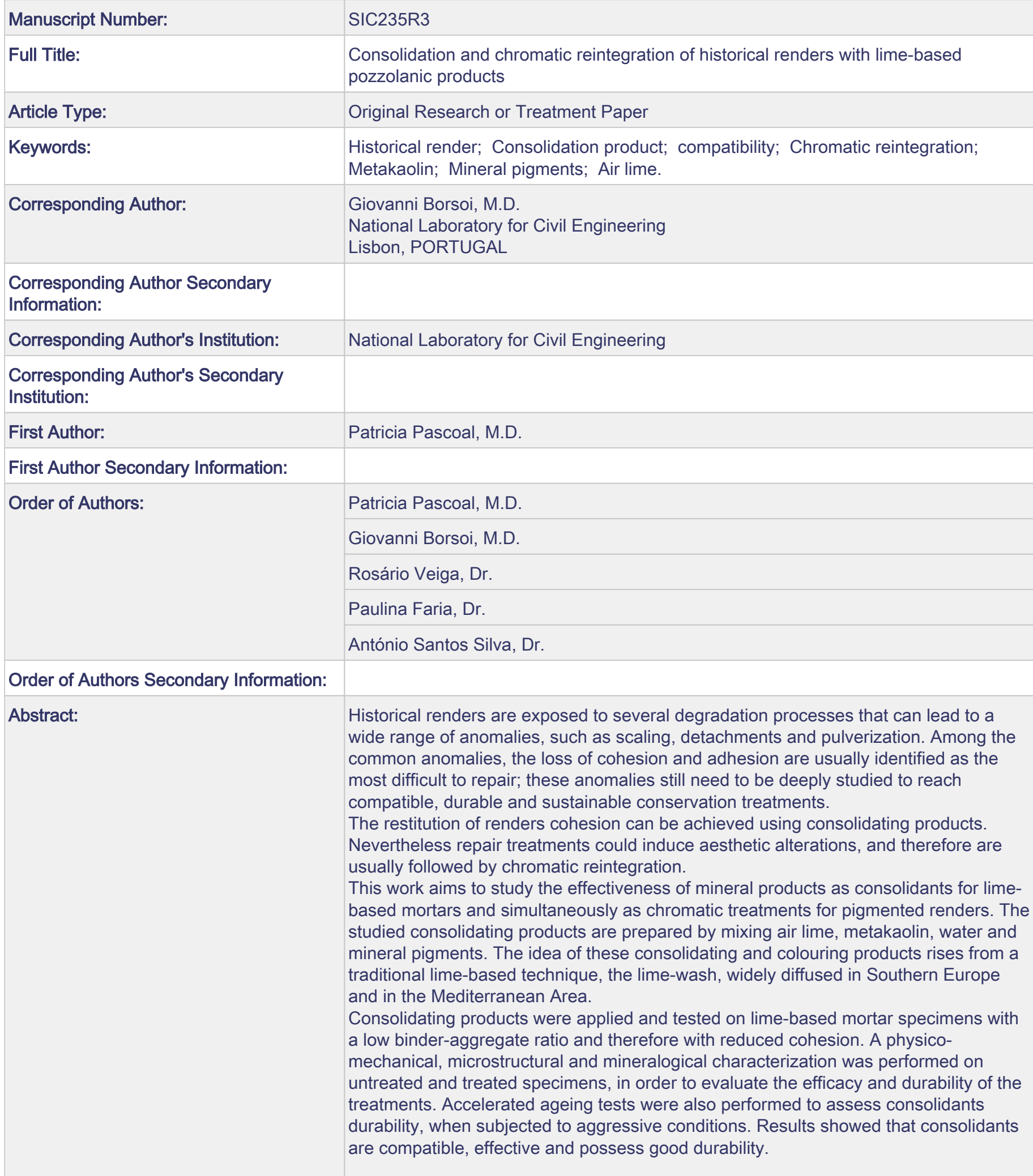




\title{
Consolidation and chromatic reintegration of historical renders with lime-based pozzolanic products
}

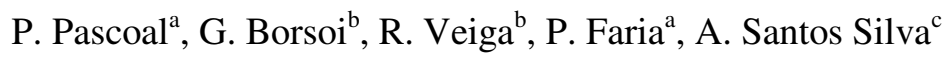 \\ ${ }^{a}$ NOVA University of Lisbon, Faculty of Science and Technology, Civil Engineering Department, UNIC, 2829-516, \\ Caparica, Portugal \\ ${ }^{\mathrm{b}}$ National Laboratory for Civil Engineering, Building Department, Av. do Brasil, n.106, Lisbon, Portugal \\ ${ }^{c}$ National Laboratory for Civil Engineering, Materials Department, Av. do Brasil, n.106, Lisbon, Portugal
}

\begin{abstract}
Historical renders are exposed to several degradation processes that can lead to a wide range of anomalies, such as scaling, detachments and pulverization. Among the common anomalies, the loss of cohesion and adhesion are usually identified as the most difficult to repair; these anomalies still need to be deeply studied to reach compatible, durable and sustainable conservation treatments.

The restitution of renders cohesion can be achieved using consolidating products. Nevertheless repair treatments could induce aesthetic alterations, and therefore are usually followed by chromatic reintegration.

This work aims to study the effectiveness of mineral products as consolidants for lime-based mortars and simultaneously as chromatic treatments for pigmented renders. The studied consolidating products are prepared by mixing air lime, metakaolin, water and mineral pigments. The idea of these consolidating and colouring products rises from a traditional limebased technique, the lime-wash, widely diffused in Southern Europe and in the Mediterranean Area.

Consolidating products were applied and tested on lime-based mortar specimens with a low binder-aggregate ratio and therefore with reduced cohesion. A physico-mechanical, microstructural and mineralogical characterization was performed on untreated and treated specimens, in order to evaluate the efficacy and durability of the treatments. Accelerated ageing tests were also performed to assess consolidants durability, when subjected to aggressive conditions. Results showed that consolidants are compatible, effective and possess good durability.
\end{abstract}

Keywords: Historical render; Consolidating product; Compatibility; Chromatic reintegration; Metakaolin; Mineral pigment; Air lime.

\section{INTRODUCTION}

Mortars have been used since ancient times as wall finishing materials and their composition varied according to the nature of the binder, but the majority of historical mortars in Europe are lime-based (Elsen, 2006). Historical building finishings are usually based on mortar renders, plasterwork and paintings. Renders perform a protective function for masonry and define the aesthetic appearance of buildings (Faria, et al., 2010). 
Their exposure to several degradation processes can lead to a wide range of anomalies; among the common defects, the most difficult to treat were identified as the loss of adhesion and of cohesion (Tavares, et al., 2008; Veiga, 2012). The latter is characterized by the loss of mechanical resistance, due to the deterioration of the binder-aggregate structure (Toniolo, et al., 2011; Borsoi, et al., 2012a).

Mortar turns friable and susceptible to material loss by several degradation processes. The presence of water or high humidity, salts crystallization, action of environmental agents or occurrence of chemical phenomena can lead to cohesion loss (Toniolo, et al., 2011; Borsoi, et al., 2012a).

The recovery of the cohesion is achieved with the application of consolidating products that penetrate in the mortar porous structure and restore the connections of the binder-aggregate system, enhancing the preservation of the original materials.

Inorganic products such as air lime, limewater, barium hydroxide or ethyl silicate present full compatibility with old renders and great durability. Limewater is one of the oldest known consolidating products, documented as a consolidant for building materials in Vitruvius De architectura (Hansen, et al., 2003). These mineral products consolidate mortars surface due to their capacity to regenerate and integrate the lost original binder (Dei \& Salvadori, 2006).

In order to achieve a suitable treatment, beyond compatibility and durability, several requirements have to be considered, such as a moderate mechanical improvement and an adequate penetration depth; finally chromatic and vapor permeability alterations of the original render must be avoided (Toniolo, et al., 2011; Hansen, et al., 2003). A methodology to assess the performance of consolidating treatments is very important and needs to be carefully defined, at short term and after natural and artificial ageing.

Conservation treatments, including consolidation, can generate chromatic alterations on buildings surface. The reproduction of similar chromatic properties in treated surfaces is a common problem for conservators (Candelaria, et al., 2008).

The renders repair, e.g. by fulfilling lacunae and cracks, generally causes aesthetic heterogeneity and prejudices the architectonic surface, sometimes dramatically. Pigmented products can be useful to operate on colored renders and on the chromatic integration of substitution renders. In cases of decohesion of colored renders, both consolidation and chromatic reintegration should be achieved.

Inorganic pigments, as earth oxides, present optimal resistance and durability to the strong alkaline environment of the lime-based consolidating products (Hradil, et al., 2003). Several archaeological studies provide documentary evidences of ochres use since pre-historic times, mainly yellow and red earths, due to their wide diffusion and high thermo-dynamical stability (Eastaugh, et al., 2004; Macdonald, et al., 2011; Bikiaris, et al., 1999).

The aim of this work is to study products able to fulfill both consolidation and chromatic reintegration functions. These consolidating products are inspired by the traditional lime-based technique of lime-washings, which are applied with diluted lime putty, sometimes mixed with inorganic pigments. These solutions are widespread in Southern Europe and in the Mediterranean area, being one of the most traditional finishing.

Most of historical buildings were coated by lime-based solutions with the addition of inorganic pigments. Lime-washings were periodically renewed as a consequence of natural deterioration along the years. These lime-based products are durable, compatible and low-cost. Nevertheless these traditional techniques are disappearing, substituted by modern products. A previous work (Tavares, et al., 2002) provided analytical data and the idea to experiment pigmented lime-based consolidants; limewater was used as consolidant, but many applications were necessary to 
achieve some efficacy for mortar with moderate cohesion loss (Tavares \& Veiga, 2006; Tavares, et al., 2008).

The mineral consolidants assessed in this study are based on air lime with the addition of a pozzolanic material (metakaolin - MK), which could improve the mechanical performances of the treated renders; two iron-based pigments, a yellow natural earth and a red synthetic iron oxide, were incorporated. These products are used for interventions on ancient colored renders, allowing simultaneous consolidation and chromatic reintegration.

The assessment of these products should include the verification of their effectiveness as consolidants, their compatibility as conservation products and their durability. The methodology used in the present study has been defined in previous works developed by the authors (Tavares, et at, 2006; Tavares, et al, 2008; Borsoi, et al, 2013a; Borsoi, et al, 2013b) and based in preceding research (Ferreira Pinto \& Delgado Rodrigues, 2008). The efficacy and compatibility were verified by comparing the results obtained in several physical-chemical tests, performed on mortars specimens before and after treatment. The aim is to achieve a moderate improvement of the cohesion, with any significant changes of the hygric behavior and of the chromatic values.

Another crucial issue is the durability of consolidating products, and little data on the effective lifespan of treatments are often provided. In this work a first assessment of durability was carried out through artificial ageing tests, consisting on a series of cycles simulating climatic variations of temperature, rain and frost (Velosa \& Veiga, 2006). The same set of physicalchemical characterization tests was performed on treated mortars after exposure to the artificial ageing cycles, comparing the results with the values obtained before ageing.

Finally, treatments' salt resistance, another important parameter for mortar durability, is not reported in this paper and was recently reported and published (Matos, et al., 2014). The durability of lime-based treatments, additivated with MK and with the same pigments as those used in the present work, was verified and underlined: indeed, it could be proved that the treatment achieved a good resistance to repeated dissolution cycles with sodium chloride aqueous solution.

The experimental procedure allowed to assess the viability, efficacy and durability of these intervention processes, namely the simultaneous consolidation and chromatic reintegration.

\section{MATERIALS}

\subsection{Mortar specimens}

Mortars with a low binder:aggregate ratio (1:4, in volume) and a binder:tap water ratio of 1:2 (by weight) were prepared, in order to simulate a mortar with cohesion loss.

Mortars were prepared by mechanically mixing lime, water and aggregates, according to the standard procedure based on the EN 1015-2:1998/A1:2006 (CEN, 2006), but adapted to limebased mortars, as follows: each mortar began with the manual homogenization of all dry materials and their introduction into the mechanical mixer container; the mechanical mixer worked at low speed and the water was introduced during the first 15 to 20 seconds; after 150 seconds the machine was stopped to scrape the borders and involve the mortar and turned on for another 30 seconds to complete the mixture (Grilo, et al., 2014).

The binder was a commercially available air lime CL90 (H100 by Lusical, Portugal). The aggregate was optimized by mixing three commercial quartzitic sands (A12, A20 and A30 by Areipor, Portugal), with volume ratio 1:1.5:1.5. The three sands present different grain size distributions and mean particle size $<2 \mathrm{~mm}$, as shown in fig. 1 . These sands are almost pure silica (quartz and quartzite), with small amount of feldspars and mica. 
Two types of mortar specimens were prepared, namely prismatic specimens (40x40x160 mm), molded according to the EN 1015-11 (CEN, 1999), and a single mortar layer of 15mm thickness applied on one surface of ceramic hollow bricks $(280 \times 190 \times 40 \mathrm{~mm}$, by Torrense Cerâmicas, Portugal).

All specimens were stored in a controlled environment at $20 \pm 2^{\circ} \mathrm{C}$ temperature $(\mathrm{T})$ and $50 \pm 5 \%$ relative humidity $(\mathrm{RH})$ for 90 days. These 3-months curing conditions are assumed to be adequate to reach reasonable lime carbonation, although it has not been directly checked (through e.g. FTIR). Lime-based mortar are indeed very porous, due to low lime content, and the applied mortar layer is thin $(15 \mathrm{~mm})$; therefore, based also on previous works and literature (Van Balen, 2005; Lanas et al., 2003; Faria, et al., 2008; Faria \& Martins, 2013), it is very probable that in 90 days a reasonable lime carbonation was achieved. In any case, it has to be stressed that all the tests were carried out on treated and untreated specimens with the same curing period, thus in similar carbonation conditions, and therefore results between treated/untreated specimens are comparable, beyond lime carbonation. After this carbonation phase, consolidating products were applied on a part of the specimens.

\subsection{Consolidating products}

\subsubsection{Materials and composition}

Previous studies (Tavares, et al., 2006; Tavares 2008), inspired by the traditional technique of limewash, analized the perfomance of aqueous lime-based product as mortars' consolidants. Results pointed out slight improvement of the mechanical strength and just a moderate durability, if applied on external renders and therefore exposed to atmospheric agents.

This paper, based on these inspiring works, aims at optimizing this consolidation technique. It is investigated whether metakaolin, added in the formulation of an aqueous lime-based product to induce some hydraulicity, can improve the durability of lime mortars.

Three different products were studied and applied on mortar specimens. The products used are composed of air lime, metakaolin, distilled water and mineral pigments. The lime was the same commercial one used for specimens production.

Metakaolin (MK), an artificial pozzolan, is a thermally activated aluminosilicate material $\left(\mathrm{Al}_{2} \mathrm{Si}_{2} \mathrm{O}_{7}\right)$ produced from the calcination of kaolin $\left(\mathrm{Al}_{2}(\mathrm{OH})_{4} \mathrm{Si}_{2} \mathrm{O}_{5}\right)$. The thermal treatment at temperatures between $600^{\circ} \mathrm{C}$ and $800^{\circ} \mathrm{C}$ causes the total or partial crystalline structure collapse of kaolin and gives rise to a reactive and amorphous phase rich in silica and alumina (Aggelakopoulou \& Bakolas, 2011).

At ambient temperature and in the presence of water, MK reacts and combines with lime, developing hydraulic products with improved mechanical and aggregating properties (Velosa 2006; Borsoi, et al. 2012b; Gameiro, et al., 2012). Among other advantages, the introduction of MK in lime-based mortars is expected to slightly reduce the permeability and to increase the mechanical resistance, as well as the chemical attack resistance, resulting in greater long-term durability (Siddique \& Klaus 2009; Faria, 2009).

Lime-pozzolan mortars have been widely used in masonry walls and renders. Exposed to high humidity conditions or in contact with water, they have proven to be durable over the centuries (Aggelakopoulou \& Bakolas, 2011).

In this study a commercial metakaolin was used (Argical M-1200S, Imerys). The modified Chapelle test was performed to determine the metakaolin pozzolanic activity, according to the NF P18-513 (AFNOR, 2010). This test concerns the measure of the $\mathrm{Ca}(\mathrm{OH})_{2}$ fixed by metakaolin when in contact with a saturated solution of $\mathrm{Ca}(\mathrm{OH})_{2}$, for a period of 16 hours at a 
temperature of $85 \pm 5^{\circ} \mathrm{C}$ (Pontes, et al., 2013; Gil, et al., 2007). Results evidence the high pozzolanic activity of metakaolin Argical M-1200S (1293 mg Ca(OH) $/ \mathrm{g})$.

Two mineral pigments were selected for chromatic reintegration: a yellow natural ochre (OA), commercialized by Fulgor, and a red synthetic iron oxide (VB), commercialized by Bayer. These pigments were chosen considering their mineralogical composition and chromatic properties. According to previous XRD analyses of several pigments and natural earths (Candelaria, et al., 2008), OA and VB are pure iron oxides containing respectively goethite and hematite.

Their colour is correlated with the presence of iron oxides, mainly goethite $(\mathrm{FeO}(\mathrm{OH}))$ and hematite $\left(\alpha-\mathrm{Fe}_{2} \mathrm{O}_{3}\right)$, that respectively represent the main chromophore for yellow and red ochres. Goethite is considered the most abundant iron oxide in nature (Elias, et al., 2006; Rakovan, et al., 1999; Marshall, et al., 2005).

There are three main factors that influence ochres chromatic properties: the iron oxide nature (chromophore), the mineralogical composition and the particle size distribution. According to the pigments origin, besides the iron oxides, natural earths can contain small amounts of other inorganic minerals (e.g., quartz, clay minerals or other metal oxides) (Candelaria, et al., 2008; Eastaugh, et al., 2004).

Based on previous experimentations (Gameiro, et al., 2012), the lime binder was replaced in $25 \%$ by MK (in weight) in order to maximize the formation of pozzolanic products and to minimize the filler effect (which leads only to pores filling).

Concerning the consolidants, a solid (lime plus metakaolin): water ratio of 1:4 in volume (1:12 in weight) was selected since it guarantees an efficient applicability, adequate penetration depth and thereby homogeneous consolidation (Borsoi, et al., 2012b). The mineral pigments were added in two different concentrations (3\% and 5\% by weight), both calculated on the weight of the dry solid materials (lime and MK). Lime and metakaolin present almost the same bulk density (respectively $398 \mathrm{~kg} / \mathrm{m}^{3}$ and $402 \mathrm{~kg} / \mathrm{m}^{3}$ ), similar as well to that of the yellow ochre (393 $\mathrm{kg} / \mathrm{m}^{3}$ ), whereas red iron oxide is more dense $\left(742 \mathrm{~kg} / \mathrm{m}^{3}\right.$ ) (Candelaria, et al., 2008). Table 1 describes the consolidants used and some important properties, as dry residues and $\mathrm{pH}$.

\subsubsection{Preparation and application}

All consolidating products were prepared by mixing the different components under magnetic stirring for 10 minutes, until complete product homogenization. Consolidants were applied using a manual spraying technique from a range of $20-30 \mathrm{~cm}$. The consolidants were nebulized in ten consecutive applications on each mortar specimen, to achieve a homogeneous distribution and a moderate surface consolidation.

After consolidation, specimens were stored for 7 days in a climatic chamber with humid conditions at $\mathrm{T}=20 \pm 2^{\circ} \mathrm{C}$ and $\mathrm{RH}=95 \pm 5 \%$ in order to promote the formation of pozzolanic products (Faria, 2009). The treated specimens were then stored in a conditioned room ( $\mathrm{T}=20 \pm 2^{\circ} \mathrm{C}, \mathrm{RH}=65 \pm 5 \%$ ), to favor the carbonation of the free lime (portlandite) still existent in the applied consolidants.

\section{TEST-METHODS}

A set of analysis was performed on treated and untreated specimens in order to assess the consolidating products efficacy and to characterize the consolidation treatments. Physicalmechanical and microstructural characterization of treated and untreated specimens was performed after 28 and 90 days from consolidant product application. 
Flexural $\left(\mathrm{R}_{\mathrm{f}}\right)$ and compressive $\left(\mathrm{R}_{\mathrm{c}}\right)$ strength tests were performed with an ETI-HMS apparatus, according to the EN 1015:11 (CEN, 1999).

The superficial hardness of mortars was determined with a mechanical durometer with a spring loaded needle-like indenter (Shore A by PCE Group, measurement range 0 to 100) based on ASTM D2240 procedure (ASTM, 2000). This equipment measures the penetration resistance of a metallic pin on the analyzed material. Measurements were performed on mortars applied on bricks, with 12 measurements/specimen.

Water absorption of the mortar specimens applied on ceramic bricks was checked with Karsten tubes, according to the methodology adopted by RILEM (RILEM, 1980). Karsten tubes test applied on untreated and treated specimens, verifies the water absorption variation due to the consolidation treatments. This test simulates the pressure of above $140 \mathrm{~km} / \mathrm{h}$ wind on the vertical surface of the specimens where pipes are applied (RILEM, 1980). Two Karsten pipes were glued with mastic adhesive to each specimen, testing 3 specimens/treatment. Values were registered in seconds.

The freshly fractured surfaces of mortar specimens of the consolidants were observed with an Olympus SZH-10 microscope. The consolidants' penetration depth was verified by observing the cross-section and comparing treated-untreated specimens. Images were recorded with an Olympus DP-20 digital microscopy camera. The Olympus LabSens software was used to record and analyze the treated mortars. The consolidants penetration depth was verified by observing the cross section of the treated mortars, measuring the average mean of at least 12 point for each treatment, using an interactive measurement tool of the Olympus LabSens software.

Microstructural observations were done on freshly fractured specimens and observed in a scanning electron microscope (SEM). Specimens were previously sputtered with a gold film and then observed in a SEM JEOL JSM-6400 coupled with an Oxford energy dispersive X-ray spectrometer (EDS).

$\mathrm{X}$-ray diffraction (XRD) analysis was used to characterize the mineralogical composition of the consolidating products. XRD analysis was performed with a Philips PW1830 generator

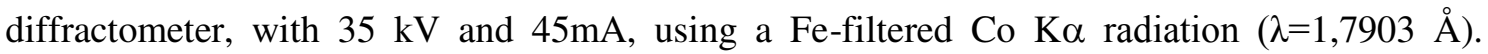
Diffractograms were recorded in the range $3-74^{\circ} 2 \theta$ with a velocity of $0,05^{\circ} 2 \theta / \mathrm{s}$.

Finally an accelerated ageing test was performed on treated mortar specimens (previously analyzed at 28 and 90 days from consolidants' application) to verify the treatments resistance to weathering cycles (Velosa \& Veiga, 2006). Mortars applied on ceramic bricks were subjected to temperature and freeze-thaw cycles. The test conditions, presented in Tab. 2, were adapted from EN 1015:21 (CEN, 2002) and represent extreme climate conditions; eight cycles of each type were performed instead of the four indicated in the EN. During this experiment the chromatic variations of the mortar specimens were evaluated with a NCS Scale. After ageing cycles, physical-mechanical tests (durometer hardness; absorption by Karsten tubes) and microscopic observations (optical microscopy; NCS scale) were repeated to compare these values with the specimens not subjected to artificial ageing and, therefore, to evaluate the specimens' durability.

\section{RESULTS AND DISCUSSION}

\subsection{Mechanical properties}

Table 3 shows the mechanical tests results of untreated and treated specimens, analyzed at 28 and 90 days after consolidation. In all cases, three prismatic specimens were analyzed.

An improvement of the mechanical characteristics of treated specimens is generally observed for MK25 treatment. 
Pigments addition evidences a typical influence on mechanical resistance, since they can cause either mechanical reduction or improvement, depending on the pigment used. VB consolidants reached lower values in flexural and compressive strength, compared to untreated treatment, probably due to pigment filler effect. OA consolidants show instead an improvement of the mechanical resistance, compared to untreated specimens, with values similar to MK25 treatment. These can be linked to the goethite reactivity, related to its surface functional hydroxyl groups (Rakovan, et. al., 1999), with air lime in an aqueous dispersion.

Considering efficacy and compatibility, consolidation treatments should moderately improve the flexural and compressive strength, namely not significantly exceeding 1.5 times the values of untreated specimens (Toniolo, et. al., 2011). In this case this condition means that flexural strength $R_{\mathrm{f}}$ should be higher than 0.42 and $0.50 \mathrm{~N} / \mathrm{mm}^{2}$ (efficacy) and not significantly exceed 0.63 and $0.80 \mathrm{~N} / \mathrm{mm}^{2}$, respectively at 28 and 90 days (compatibility), while compressive strength $\mathrm{R}_{\mathrm{c}}$ should be higher than 0.62 and $0.64 \mathrm{~N} / \mathrm{mm}^{2}$ and not be much higher than 0.93 $\mathrm{N} / \mathrm{mm}^{2}$, both at 28 and $90 \mathrm{~d}$. As seen in table 3 the condition for compatibility is fulfilled and in most cases the increase of mechanical resistance, although non significant, points out some efficacy.

The flexural strength/compressive strength ratio, uncommonly high for the untreated specimens due to the deformability of the low binder mortar, became close to 0.5 after treatments, which is the normal ratio for air lime mortars (Veiga et al., 2010).

\subsection{Durometer hardness}

Figure 2 shows the results obtained at different ages (28 and 90 days) and after accelerated ageing. An improvement of the superficial hardness is evident in all the treated specimens. The results of the treated specimens are quite similar, with a moderate improvement of superficial hardness compared to untreated specimen. The increase of the superficial hardness after different periods of time is on average 7 points of hardness Shore A. The standard deviation, although a reasonable number of measurements were collected, is remarkable due to the intrinsic heterogeneity of the mortar specimens. It should be stressed that superficial hardness was assessed on mortars applied on bricks, which, compared to prismatic specimens, are more representative of a real study case; a render or plaster is by definition applied on a substrate.

The addition of inorganic pigments does not induce any notable decrease on the superficial hardness, as the results are similar to those obtained on specimens treated with MK25.

Finally, after accelerated ageing test, hardness values slightly decrease, but values are almost unaltered (variation of 0.5 to 2 points of hardness Shore A), demonstrating treatments' durability. Concerning pigmented treatments, VB treatments show slightly higher values, after accelerated ageing, compared to OA treatments.

\subsection{Karsten tubes}

Water absorption times are presented in Fig. 3. The reduction of water absorption is evident in all the treated specimens, and absorption times of some treated specimens were more than 10 times higher than those of untreated specimen.

At 28 and 90 days VB5 treatments reached values similar to MK25 treatment, while OA5 presents the lowest water absorption reduction. However, after accelerated ageing, OA treatments show the highest reduction of water absorption compared to untreated specimens. The results show that the increase of pigments concentration (3\% to 5\%) led to lower absorption times; absorption rate increases with an increasing amount of pigment in the consolidating products, probably due to the high specific surface of the pigments. 
Results evidence high variability and standard deviations due to the high heterogeneity and porosity of the treated mortars. However all the values are still low, barely reaching 5 minutes (in two cases after ageing), evidencing a relatively high water absorption. Consolidating treatments are therefore moderate and do not change excessively the consolidated specimens' water absorption.

\subsection{Stereozoom microscopy observations}

Specimens' cross sections were analyzed and the consolidants' penetration depth was evaluated by comparing treated/untreated mortars. Treated mortars present compact surfaces and reduced porosity, compared to untreated mortar (Figs. 4a, 4b, 4c). Consolidating products are welldistributed and do not create a superficial patina on the treated mortar, avoiding a strong modification of water absorption, as seen in the previous section.

The stereozoom microscopic observations of the treated mortars illustrate the presence of white spherical formations (Fig. 4d) both on aggregate and on the original binder matrix, with diameter sizes ranging from 20 to $230 \mu \mathrm{m}$.

Figures 5a and 5b illustrate the penetration depth of OA5 and VB5 treatments. Consolidating products present heterogeneous depth distribution, due to mortar heterogeneity, varying in a large range between $1.2 \mathrm{~mm}$ and $6.5 \mathrm{~mm}$. Depth penetration mean values (12 measurements/treatment) of OA5 and VB5 are $2.1 \mathrm{~mm}$ and $3.1 \mathrm{~mm}$, respectively, showing that VB5 penetrates more than OA5.

\subsection{Microscopic observations by SEM-EDS}

Consolidants' distribution appears to be homogeneous, which is consistent with the mechanical resistance improvement and the moderate water absorption reduction of treated mortars, as seen in previous sections.

The microstructural analysis of treated specimens shows that the amount of neoformation pozzolanic compounds is minimal in all treatments. The main pozzolanic products, which can be produced from the reaction lime-metakaolin, can be divided in 3 groups: calcium silicate hydrates $(\mathrm{CSH})$, calcium silico-aluminates hydrates $(\mathrm{CASH})$ and calcium aluminate hydrates (CAH). These products can be identified on observation of their morphology and also through their EDS spectrum, which shows aluminum, silicium and calcium peaks with specific intensity ratios (Al, Si, Ca) (Chen, et al., 2004; Santos Silva, et al., 2004).

In this case, consolidation effect is mostly linked to lime carbonation, since EDS analysis illustrates the presence of high amounts of calcite $\left(\mathrm{CaCO}_{3}\right)$ and portlandite. However, Fig. 6a evidences traces of acicular formations, which, based also on their EDS spectra (Fig. 6b), could be identified as calcium-aluminum hydrates $(\mathrm{CAH})$ or amorphous calcium-silicate hydrates (CSH).

Spherical formations detected previously by optical microscopy (section 4.4.1) were analyzed by SEM-EDS. EDS analysis shows that these formations are mostly calcite crystals and, in a more reduced quantity, a blend of calcite and hydraulic compounds. These spherical formations are probably caused by the wet storage conditions $(95 \% \mathrm{RH})$, performed in the first 7 days in the treated mortars. High RH conditions might encourage lime-based aggregation on the surface; in a later stage of the storage (at $65 \% \mathrm{RH}$ ), these aggregates undergo carbonation, leaving these unwanted formations on the surface.

Concerning pigmented consolidating products, inorganic iron-based pigments show mostly a filler effect. The low pigment percentage contributes to densify the original matrix, filling 
partially mortars pores and voids (Braga, et al., 2012). Iron oxides were identified on mortar surface, but red and yellow earth pigments show some differences in their microstructure. .

The microstructural observations of specimens treated with VB5 (Fig. 7a) evidence that the presence of hematite might influence the formation of pozzolanic compounds. Hematite indeed does not react with lime and just works as filler (Fig. $7 \mathrm{~b}$ and $7 \mathrm{c}$ ). On the other hand, several authors (Rakovan, et al., 1999; Marshall, et al., 2005) report that goethite reacts with lime and carbonates. Goethite small grain size $(0.1 \mu \mathrm{m})$ and high surface area $\left(100-200 \mathrm{~m}^{2} / \mathrm{g}\right)$ contribute to its high reactivity and high affinity for sorption of many cations and anions. Goethite binding energy is higher than that of hematite (Stipp \& Hochella, 1991). McIntyre and Zetaruk (1977) demonstrated that this higher binding energy reflects the interactions between the proton on the $\mathrm{OH}$ group and the non-protonated oxygen of the goethite structure. Moreover goethite presents a notable carbonate anions' absorption capacity (Villalobos, et al., 2003), which increases with $\mathrm{pH}$ (in this case $\mathrm{pH}>12$ ) and specific surface area.

Goethite is therefore reactive with calcium hydroxide (Fig. 8a) and absorbs carbonate anions. Traces of pozzolanic compounds were indeed identified also in the proximity of goethite; it is anyway not clear if this yellow iron oxide inhibits or negatively influences the formation of pozzolanic compounds (Fig. 8b).

\subsection{XRD analysis}

The mineralogical compositions of MK25, OA5 and VB5 were determined by XRD. Consolidating products pastes were placed in Petri disks and stored during 7 days at different curing conditions (50\% RH and $95 \% \mathrm{RH})$. The aim was to confirm the possibility of occurrence of pozzolanic formations at 7 days, due to the high and quick MK/lime reactivity, besides the efficacy of the curing condition and the pigments influence on the consolidating products.

Table 4 shows the qualitative and semi-quantitative mineralogical composition of the consolidants. As expected, dryer RH promotes lime carbonation reaction, and consolidating products stored at 50\% RH present higher amount of calcite. 95\% RH storage condition shows, on the other hand, a slight improvement on pozzolanic compounds.

The pozzolanic products identified in all consolidant samples are calcium-aluminate hydrate $(\mathrm{CAH})$, monocarboaluminate $(\mathrm{CCA})$ and hydrogarnet. The presence of CCA and CAH guarantees an improvement of the mechanical resistance, while the presence of hydrogarnet (in traces compared to the other pozzolanic products) at both curing conditions could be prejudicial. Hydrogarnet is in fact a metastable product, which may lead to an increase of porosity and a decrease in mechanical strength (Gameiro, et al., 2012). Amorphous compounds, as calciumsilicate hydrates $(\mathrm{CSH})$, cannot be identified by XRD analysis and, therefore, the presence of possible traces of CSH cannot be confirmed.

Experimental results evidence that 95\% RH improves the formation of CAH. Recent studies with lime-metakaolin pastes and mortars show that a significant part of the monocarboaluminate and calcium-aluminate hydrate phases are also metastable compounds, which may cause a reduction of the mechanical resistance in the first months (Gameiro, et al., 2012). This evidence could justify the fact that some mechanical values decreased at 90 days, compared to the results obtained at 28 days.

Inorganic pigment additions do not interfere significantly in the mineralogical composition (e.g. pozzolanic compound as $\mathrm{CAH}$ or hydrogarnet) of the consolidant. Quartz was also found in all samples indicating its presence in MK. 


\subsection{Accelerated ageing test}

Treated and untreated mortar specimens applied on bricks, after having completed 90 days since consolidants' application, were subjected to an accelerated ageing test by climatic cycles.

Treated specimens appear well-resistant to temperature cycles. Freeze-thaw cycles are expected to be more aggressive with tested mortars and, as a matter of fact, these conditions caused greater deterioration, especially on untreated specimens. Freeze process lead to a volume increase of the absorbed water, which solidified inside the inner pores, originating microtensions in the mortars structure and causing internal damages that affect mortar stability and durability.

After freeze-thaw cycles, the treated specimens showed some cracking in the superficial layer with a reduced material loss. Untreated specimens showed instead severe degradation and material loss (Fig. 8a), since just above $25 \%$ of the initial mortar specimen was preserved. Compared to the untreated mortars, consolidant treatments demonstrate to improve the mechanical resistance and durability, as seen in previous sections, avoiding cracking and disaggregation (Fig. 8b, 8c and 8d). VB5 treatment showed higher durability compared to OA5, confirming the previous mechanical measurements.

Salt resistance of the pigmented and unpigmented consolidant products was presented in another work (Matos, et al., 2014) and treated mortars demonstrated a good resistance to repeated dissolution-crystallization cycles (up to 5 cycles) with aqueous solution of sodium chloride. These findings are in agreement with other studies (Kaid, et al., 2009; Khater, 2010; Pavlík, 2010) presented in literature dealing with application of fine grained mineral admixtures for improvement of the mortar and concrete resistance to salt attack. The incorporation of supplementary materials such as blast-furnace slag, fly ash, silica fume, metakaolin, and different types of natural pozzolana as a partial replacement of the binder has been found to be beneficial for the improvement of the resistance to water ingress and chloride and sulphate attack. The presence of MK influences the structure and porosity of the treated mortars, influencing as well the chloride diffusion coefficient (Kaid, et al., 2009). This allows a reduction of microtensions created by the recrystallization of sodium chloride and an increase of substrate durability.

\subsubsection{Chromatic variations}

Table 5 illustrates the chromatic alterations that occurred on treated specimens after accelerated ageing test. Untreated specimens and those treated with MK25 presented minimal chromatic variations, maintaining almost the same color values (S0502-Y and S0500-N, respectively). The referred values of the NCS scale can be verified in the NCS interactive navigator (http://www.ncscolour.com/en/ncs/ncs-navigator/).

Freeze-thaw cycles induce reduced chromatic variations, indicating that consolidant treatments are durable and pigments are well-incorporated in the consolidating products.

Goethite-based ochre (OA) presents suitable coloring strength, due to its possible reaction with lime and absorption of carbonates, as seen in the previous sections; nevertheless OA treatments tend to slightly darken.

VB treatments bleach slightly and present lower chromatic alterations compared to OA. Synthetic hematite-based pigments (VB) are inert and do not react with lime, due to its higher stability, which contribute to a long-term durability (Rakovan, et at., 1999; Rocha-Gomes, et al., 2007).

\section{CONCLUSIONS}


Consolidating products considered in this work proved to be effective and physico-chemically compatible with the treated lime mortars. The consolidation process occurred mostly due to lime carbonation but, on the other hand, the formation of crystalline pozzolanic compounds is confirmed by XRD, although in reduced amounts. Longer wet curing would possibly have induced higher amount of pozzolanic formations and more stable compounds.

The analyzed products achieved an appropriate consolidation in terms of:

- Moderate improvement of the mechanical resistance and of the superficial hardness;

- Beneficial but moderate water permeability reduction;

- Homogenous consolidation, partial pore infilling;

- Adequate penetration depth of the consolidating products;

- High resistance to climatic cycles, indicating acceptable long-term durability to climatic variations.

Concerning chromatic reintegration, pigmented products conferred homogeneous appearance on mortar surface and no significant decreasing influence on the consolidants' efficacy. Inorganic pigments appear to be well-fixed in the consolidant treatment and demonstrated to remain stable after accelerated ageing test. Nevertheless more data would be interesting to estimate long-term strength. Comparing to the ochre earth pigment (OA - goethite), which is able to react and absorb carbonates, the synthetic red iron oxide (VB - hematite) presents higher chromatic stability, being appropriate for interventions on (external) renders. OA treatments, instead, due to their greater chromatic variations with ageing, are more appropriate to use in indoor interventions on plasters.

The obtained values reflected therefore good results for pigmented consolidating products, with adequate binder-aggregate re-aggregation effect, compatibility and durability to artificial aging. The possibility to act simultaneously on chromatic reintegration and consolidation intervention represents a remarkable advantage for the conservation of colored historical renders.

\section{ACKNOWLEDGEMENTS}

This study was developed within Project Limecontech - Conservation and durability of historical renders: compatible techniques and materials, financed by FCT - Fundação para a Ciência e a Tecnologia (Portugal). Special thanks go to Bento Sabala for mechanical tests support.

\section{REFERENCES}

AFNOR - Association Française de Normalisation 2010. Metákaolin, addition pouzzolanique pour betóns - Definitions, specifications, critéres de conformité. France: AFNOR, NF P18-513.

ASTM - American Society for Testing and Materials, 2000. Standard test method for rubber property - durometer hardness. United States: ASTM Standards. ASTM D2240-00.

Aggelakopoulou, E. \& Bakolas, A. 2011. Properties of lime-metakaolin mortars for the restoration of historic masonries, Applied Clay Science, 53: 15-19.

Bikiaris, D., Daniilia, S., Sotiropoulou, S., Katsimbiri, O., Pavlidou, E., Moutsatsou, A.P., Chryssoulakis, Y. 1999. Ochre-differentiation through micro-Raman and micro-FTIR spectroscopies: application on wall paintings at Meteora and Mount Athos, Greece, Spectrochimica Acta Part A, 56: 3-18. 
Borsoi, G., Tavares, M., Veiga, R., Santos Silva, A. 2012a. Microstructural characterization of consolidants products for historical renders: an innovative nanostructured lime dispersion and a more traditional ethyl silicate limewater solution, Microscopy and Microanalysis, 18: 1181-1189.

Borsoi, G., Veiga, R., Santos Silva, A. 2012b. Consolidation of historic mortar renderings with compatible products: evaluation of effectiveness (in Portuguese), in: IV Portuguese Congress on Mortars and ETICS, Coimbra University, 29-30 March, Coimbra (CD).

Borsoi, G., Tavares, M., Veiga, M. R., Santos Silva, A. 2013a. Studies of the performance of nanostructed and other compatible consolidation products for historical renders, Materials Science Forum, 730-732: 942-947.

Borsoi, G., Veiga, M. R., Santos Silva, A. 2013b. Effect of lime-based and silica-based products on the consolidation of historical renders, in: $3^{\text {rd }}$ Historic Mortar Conference HMC2013, 11-14 September, Glasgow (CD).

Candelária, P., Tavares, M., Veiga, R., Coroado, J.P., Costa, F. 2008. Chromatic reintegration of lime renders, in: $1^{\text {st }}$ Historical Mortars Conference HMC08, LNEC, September 24-26, Lisbon (CD).

CEN - European Committee of Standardization, 1999. Methods of test for mortar for masonry - Part 11: determination of flexural and compressive strength of hardened mortar. Brussels: CEN, EN 1015-11.

CEN - European Committee of Standardization, 2002. Methods of test for mortar for masonry - Part 21: determination of the compatibility of one-coat renderings mortars with substrates. Brussels: CEN, EN 1015-21.

CEN - European Committee of Standardization, 2006. Methods of test for mortar for masonry - Part 2: Bulk sampling of mortars and preparation of test mortars. Brussels: CEN, EN 1015-2:1998/A1.

Chen, J. J., Thomas, J. J., Taylor, H. F. W., Jennings, H. M., 2004. Solubility and structure of calcium silicate hydrate, Cement and Concrete Research, 34: 1499-1519.

Dei, L. \& Salvadori, B. 2006. Nanotechnology in cultural heritage conservation: nanometric slaked lime saves architectonic and artistic surfaces from decay, Journal of Cultural Heritage, 7: 110-115.

Eastaugh, N., Walsh, V., Chaplin, T., Siddall, R. 2004. The pigment compendium: a dictionary of historical pigments, Elsevier Butterworth-Heinemann, Oxford.

Elias, M., Chartier, C., Prévot, G., Garay, H., Vignaud, C. 2006. The colour of ochres explained by their composition, Materials Science and Engineering B, 127: 70-80.

Elsen, J. 2006. Microscopy of historic mortars - a review, Cement and Concrete Research, 36: 1416-1424.

Faria, P, Henriques, F., Rato, V. 2008. Comparative evaluation of aerial lime mortars for architectural conservation. J. Cultural Heritage 9 (3): 338-346.

Faria, P. 2009. Resistance to salts of lime and pozzolan mortars, in: RILEM Proceedings PRO 067 - Repair Mortars for Historic Masonry, Techn. Univ. Delft, The Netherlands, pp. 99-110.

Faria, P., Tavares, M., Menezes, M., Veiga, R., Margalha, G. 2010. Traditional Portuguese techniques for application and maintenance of historic renders, in: RILEM Proceedings Pro $078-2^{\text {nd }}$ Historical Mortars Conference HMC10 and RILEM 203-RHM Final Workshop, September 22-24, Prague, pp. 609-617.

Faria, P., Martins, A. 2013. Influence of lime type and curing conditions on lime and lime-metakaolin mortars, in: Durability of Building Materials and Components (V.Freitas, J. Delgado, eds.), Building Pathology and Rehabilitation, vol. 3, VIII, 105-126. 
Ferreira Pinto, A.P., Delgado Rodrigues, J. 2008. Stone consolidation: The role of the treatment procedures, Journal of Cultural Heritage, 9: 38-53.

Gameiro, A., Santos Silva, A., Veiga, R., Velosa, A. (2012). Lime-metakaolin hydration products: a microscopy analysis, Materials and Technology, Vol. II, 46: 145-148.

Gil, M., Carvalho, M. L., Seruya, A., Candeias, A.E., Mirão, J., Queralt, I. 2007. Yellow and red ochre pigments from southern Portugal: elemental composition and characterization by WDXRF and XRD, Nuclear Instruments and Methods in Physics Research A, 580: 728-731.

Grilo, J., Faria, P., Veiga, R., Santos Silva, A., Silva, V., Velosa, A. 2014. New natural hydraulic lime mortars Physical and microstructural properties in different curing conditions, Construction and Building Materials, 54: 378-384.

Hansen, E., Doehne, E., Fidler, J., Larson, J., Martin, B., Matteini, M., RodriguezNavarro, C., Pardo, E.S., Price, C., de Tagle, A., Teutonico, J.M., Weiss, N. 2003. A review of selected inorganic consolidants and protective treatments for porous calcareous materials, Reviews in Conservation, 4: 13-25.

Hradil, D., Grygar, T., Hradilová, J., Bezdicka, P. 2003. Clay and iron oxide pigments in the history of painting, Applied Clay Science, 22: 223-226.

Kaid, N. Cyr, M., Julien, S., Khelafi, H. 2009. Durability of concrete containing a natural pozzolan as defined by a performance-based approach, Construction and Building Materials, 23: 3457-3467.

Khater, H.M. 2010 Influence of metakaolin on resistivity of cement mortar to magnesium chloride solution, Ceramics, 54 (4): 325-333.

Lanas, J., Alvarez-Galindo, J. 2003. Masonry repair lime-based mortars: factors affecting the mechanical behavior, Cement and Concrete Research, 33: 1867-1876.

Macdonald, B., Hancock, R., Cannon, A., Pidruczny, A. 2011. Geochemical characterization of ochre from central coastal British Columbia, Canada, Journal of Archaeological Science, 38: 3620-3630.

Marshall, L.R., Williams, J.R., Almond, M.J., Atkinson, S.D.M., Cook, S.R., Matthews, W., Mortimore, J.L. 2005. Analysis of ochres from Clearwell Caves: the role of particle size in determining colour, Spectrochimica Acta Part A, 61: 233-241.

Matos, M., Borsoi, G., Veiga, M.R., Faria, P., Santos Silva, A. 2014. Durability to marine environment of innovative products for consolidation and chromatic reintegration of historical render, in: $9^{\text {th }}$ International Masonry Conference - IMC14, 7-9 July, Guimarães, Portugal.

McIntyre, N.S., Zetaruk, D.G. 1997. X-ray photoelectron spectroscopic studies of iron oxides, Analytical Chemistry, 49: 1521-1529.

Pavlík, Z., Pavlíková, M., Benešová, H., Mihulka, J., Fiala, L., Erný, R. 2010. Effect of metakaolin addition on the moisture and chloride transport and storage properties of high performance concrete, in Modern Building Materials, Structures and Techniques, Vilnius, 19-21 May, p. 239-244.

Pontes, J., Santos-Silva, A., Faria, P. 2013. Evaluation of pozzolanic reactivity of artificial pozzolans, Materials Science Forum, 732: 433-438.

Rakovan, J., Becker, U., Hochella, M.F. 1999. Aspects of goethite surface microtopography, structure, chemistry, and reactivity, American Mineralogist, 84: 884-894.

RILEM - Réunion Internationale des Laboratoires d'Essais et de Recherches sur les Matériaux et les Constructions, 1980. Water absorption under low pressure - Pipe method. Test NoII.4, Tentative Recommendation. In Matériaux de Construction, vol. 13, No. 75, Paris: RILEM. 
Rocha-Gomes, L., Alvarez, C. (2007). Critical analysis of environmental aspects on the use of pigments on masonry mortars in Espírito Santo (Brazil) (in Portuguese), in: II Portuguese Congress on Mortars, FIL, 22-23 November, Lisbon (CD).

Santos Silva, A., Gameiro, A., Grilo, J., Veiga, R., Velosa, A. 2014. Long-term behavior of lime-metakaolin pastes at ambient temperature and humid curing condition, Applied Clay Science, 88-89: 49-55.

Siddique, R. \& Klaus, J. 2009. Influence of metakaolin on the properties of mortar and concrete: a review, Applied Clay Science, 43: 392-400.

Stipp, S.L., Hochella, M.F. 1991. Structure and bonding environments at the calcite surface as observed with X-ray photoelectron spectroscopy (XPS) and low energy electron diffraction (LEED), Geochimica et Cosmochimica Acta, 55: 1723-1736.

Tavares, M., Gonçalves, T., Aguiar, J., 2002. Chromatic studies on ancient buildings experimental study of limewashes for external surfaces (in Portuguese), Report 086/2002, LNEC, Lisbon.

Tavares, M., Veiga, M.R. 2006. Conservation of old renderings - the consolidation technique through traditional and sustainable materials: the lime water, in: Heritage, Weathering and Conservation - HWC 2006, 21-24 June, Madrid.

Tavares, M., Veiga, R., Fragata, A. 2008. Conservation of old renderings - the consolidation of rendering with loss of cohesion, in: $1^{\text {st }}$ Historical Mortars Conference HMC08, LNEC, September 24-26, Lisbon.

Toniolo, L., Paradisi, A., Goidanich, S., Pennati, G. 2011. Mechanical behavior of lime based mortars after surface consolidation, Construction and Building Materials, 25: 15531559.

Van Balen, K. 2005. Carbonation reaction of lime, kinetics at ambient temperature. Cement and Concrete Research, 35: 647-657.

Veiga, M.R., Fragata, A., Velosa, A.L., Magalhães, A.C., Margalha, M.G. (2010). Lime-based mortars: Viability for use as substitution renders in historical buildings, International Journal of Architectural Heritage, 4(2): 177-195.

Veiga, R. 2012. Conservation of historic masonry renderings. Treatment and consolidation versus substitution (in Portuguese), in: $4^{\circ}$ Congreso de Patologia y Rehabilitación de Edificios - PATORREB 2012, 12-14 Abril, Santiago de Compostela (CD).

Velosa, A., 2006. Lime-pozzolan mortars for old renderings (in Portuguese), Ph.D. Thesis, Aveiro University, Portugal.

Velosa, A., Veiga, M.R. 2006. Development of artificial ageing tests for renders Application to conservation mortars, in: 7th International Masonry Conference - 7IMC, 30 October - 1 November, London.

Villalobos, M., Trotz, M.A., Leckie, J.O. 2003. Variability in goethite surface site density: evidence from proton and carbonate sorption, Journal of Colloid and Interface Science, 268: 273-287.

\section{TABLES CAPTIONS}


Tab. 1: Consolidants identification and composition, solid:liquid ratio, $\mathrm{pH}$ and dry residue. $\mathrm{MK}=$ metakaolin, $\mathrm{OA}=$ yellow ochre (goethite), $\mathrm{VB}=$ red Bayern (hematite).

Tab. 2: Accelerated ageing test conditions.

Tab. 3: Flexural $\left(\mathrm{R}_{\mathrm{f}}\right)$ and compressive $\left(\mathrm{R}_{\mathrm{c}}\right)$ strength results (average values and relative standard deviations).

Tab. 4: Mineralogical composition of the consolidant treatments assessed by XRD.

Tab. 5: Chromatic variations (NCS index) before and after accelerated ageing test.

\section{FIGURES CAPTIONS}

Fig.1: Particle size distribution of the three single sands A12, A20 and A30 and of their mixture (1:1,5:1,5 in volume), used for the specimens' preparation.

Fig. 2: Superficial hardness results (average values and standard deviation).

Fig. 3: Karsten tubes test results (average values and standard deviation).

Fig. 4: Stereozoom microphotographs of (a) untreated specimen, (b) MK25, (c) OA5 and (d) detail of white formations with MK25 treatment.

Fig. 5: Stereozoom images showing penetration depth measurements of (a) OA5 and (b) VB5.

Fig. 6: SEM microphotographs of the specimen treated with MK25, where (a) arrows indicate pozzolanic products formations confirmed by (b) its corresponding EDS spectrum.

Fig. 7: (a) SEM microphotograph of the specimen treated with VB5; EDS analyses confirm that (b) the presence of hematite interferes in the formation of pozzolanic formations, (c) which are more abundant and developed when iron oxide are absent.

Fig. 8: (a) SEM microphotograph of the specimen treated with OA5; EDS analysis (b) confirm that the presence of goethite does not interfere in the formation of pozzolanic neoformations.

Fig. 9: Photographs of specimens after accelerated ageing test: a) untreated; b) MK25; c) OA5; d) VB5. 
Tab. 1: Consolidants identification and composition, solid:liquid ratio, $\mathrm{pH}$ and dry residue. MK = metakaolin, $\mathrm{OA}=$ yellow ochre (goethite), $\mathrm{VB}=$ red Bayern (hematite)

\begin{tabular}{|c|c|c|c|c|}
\hline Identification & Products composition & $\begin{array}{c}\text { Solid:liquid } \\
\text { ratio }\end{array}$ & $\mathbf{p H}$ & $\begin{array}{c}\text { Dry residue } \\
(\mathbf{g} / \mathbf{L})\end{array}$ \\
\hline MK25 & Lime + MK $(25 \%)+\mathrm{H}_{2} \mathrm{O}$ & $1: 4$ & 12,4 & 75,0 \\
\hline $\mathbf{O A 3}$ & $\begin{array}{c}\text { Lime }+\mathrm{MK}(25 \%)+3 \% \\
\mathrm{OA}+\mathrm{H}_{2} \mathrm{O}\end{array}$ & $1: 4$ & 12,3 & 75,9 \\
\hline $\mathbf{O A 5}$ & $\begin{array}{c}\text { Lime }+\mathrm{MK}(25 \%)+5 \% \\
\mathrm{OA}+\mathrm{H}_{2} \mathrm{O}\end{array}$ & $1: 4$ & 12,2 & 76,3 \\
\hline $\mathbf{V B 3}$ & $\begin{array}{c}\text { Lime }+\mathrm{MK}(25 \%)+3 \% \\
\mathrm{VB}+\mathrm{H}_{2} \mathrm{O}\end{array}$ & $1: 4$ & 12,3 & 76 \\
\hline $\mathbf{V B 5}$ & $\begin{array}{c}\text { Lime }+\mathrm{MK}(25 \%)+5 \% \\
\mathrm{VB}+\mathrm{H}_{2} \mathrm{O}\end{array}$ & $1: 4$ & 12,1 & 76,5 \\
\hline
\end{tabular}

Tab. 2: Accelerated ageing test conditions.

\begin{tabular}{|c|c|c|}
\hline Temperature cycles & Freeze-thaw cycles & Exposure time (h) \\
\hline Infrared lamps $\left(60 \pm 5^{\circ} \mathrm{C}\right)$ & Sprinkler system $($ simulating rain $)$ & 8 \\
\hline Stabilization $\left(20^{\circ} \mathrm{C}, 65 \% \mathrm{RH}\right)$ & Stabilization $\left(20^{\circ} \mathrm{C}, 65 \% \mathrm{RH}\right)$ & $1 / 2$ \\
\hline Deep freeze cabinet $\left(-15^{\circ} \mathrm{C}\right)$ & Deep freeze cabinet $\left(-8^{\circ} \mathrm{C}\right)$ & 15 \\
\hline Stabilization $\left(20^{\circ} \mathrm{C}, 65 \% \mathrm{RH}\right)$ & Stabilization $\left(20^{\circ} \mathrm{C}, 65 \% \mathrm{RH}\right)$ & $1 / 2$ \\
\hline
\end{tabular}

Tab. 3: Flexural $\left(R_{f}\right)$ and compressive $\left(R_{c}\right)$ strength results (average values and relative standard deviations).

\begin{tabular}{|c|c|c|c|c|}
\hline \multirow{2}{*}{ Product } & \multicolumn{2}{|c|}{$\mathbf{R}_{\mathbf{f}}\left[\mathbf{N} / \mathbf{m m}^{2}\right]$} & \multicolumn{2}{c|}{$\mathbf{R}_{\mathbf{c}}\left[\mathbf{N} / \mathbf{m m}^{2}\right]$} \\
\cline { 2 - 5 } & $\mathbf{2 8}$ days & $\mathbf{9 0}$ days & $\mathbf{2 8 ~ d a y s}$ & $\mathbf{9 0}$ days \\
\hline Untreated & $0,42 \pm 0,03$ & $0,50 \pm 0,03$ & $0,62 \pm 0,09$ & $0,64 \pm 0,09$ \\
\hline MK25 & $0,56 \pm 0,05$ & $0,50 \pm 0,05$ & $0,91 \pm 0,12$ & $0,80 \pm 0,17$ \\
\hline OA3 & $0,55 \pm 0,05$ & $0,60 \pm 0,10$ & $0,73 \pm 0,12$ & $0,95 \pm 0,05$ \\
\hline OA5 & $0,58 \pm 0,03$ & $0,57 \pm 0,06$ & $0,68 \pm 0,13$ & $0,87 \pm 0,11$ \\
\hline VB3 & $0,58 \pm 0,03$ & $0,48 \pm 0,10$ & $0,70 \pm 0,06$ & $0,73 \pm 0,08$ \\
\hline VB5 & $0,48 \pm 0,08$ & $0,45 \pm 0,07$ & $0,73 \pm 0,08$ & $0,80 \pm 0,05$ \\
\hline
\end{tabular}


Tab. 4: Mineralogical composition of the consolidant treatments assessed by XRD.

\begin{tabular}{ccccccc}
\hline Crystalline & & $\mathbf{5 0 \%}$ RH & & \multicolumn{3}{c}{ 95\% RH } \\
phases & MK25 & OA5 & VB5 & MK25 & OA5 & VB5 \\
& & & & & & \\
\hline Quartz & ++ & ++ & ++ & ++ & ++ & ++ \\
Calcite & +++ & +++ & +++ & ++ & ++ & ++ \\
Portlandite & ++ & ++ & ++ & +++ & +++ & +++ \\
CCA & ++ & ++ & ++ & +++ & +++ & +++ \\
CAH & + & + & + & ++ & ++ & ++ \\
Hydrogarnet & + & + & + & + & + & + \\
Goethite & - & + & - & - & + & - \\
Hematite & - & - & + & - & - & +
\end{tabular}

Peak intensity: +++ high, ++ medium, + low, T traces, - undetected $\mathrm{CAH}$ - Calcium-aluminate hydrate; CCA - Monocarboaluminate

Tab. 5: Chromatic variations (NCS index) before and after accelerated ageing test.

\begin{tabular}{|c|c|c|c|c|c|c|}
\hline Specimens & Untreated & MK25 & OA3 & OA5 & VB3 & VB5 \\
\hline Before & $\begin{array}{c}S \\
0502-Y\end{array}$ & $\begin{array}{c}S \\
0500-N\end{array}$ & $\begin{array}{c}S \\
0520- \\
\text { Y10R }\end{array}$ & $\begin{array}{c}S \\
0530-Y\end{array}$ & $\begin{array}{c}S \\
1020-R\end{array}$ & $\underset{1030-R}{S}$ \\
\hline After & $\begin{array}{c}S \\
0502-Y\end{array}$ & $\begin{array}{c}S \\
0500-N\end{array}$ & $\begin{array}{c}\mathrm{S} \\
0530- \\
\mathrm{Y} 10 \mathrm{R}\end{array}$ & $\begin{array}{c}\mathrm{S} \\
0540- \\
\mathrm{Y} 20 \mathrm{R}\end{array}$ & $\begin{array}{c}\mathrm{S} \\
0520- \\
\mathrm{R} 10 \mathrm{~B}\end{array}$ & $\begin{array}{c}S \\
0530- \\
\text { R10B }\end{array}$ \\
\hline
\end{tabular}




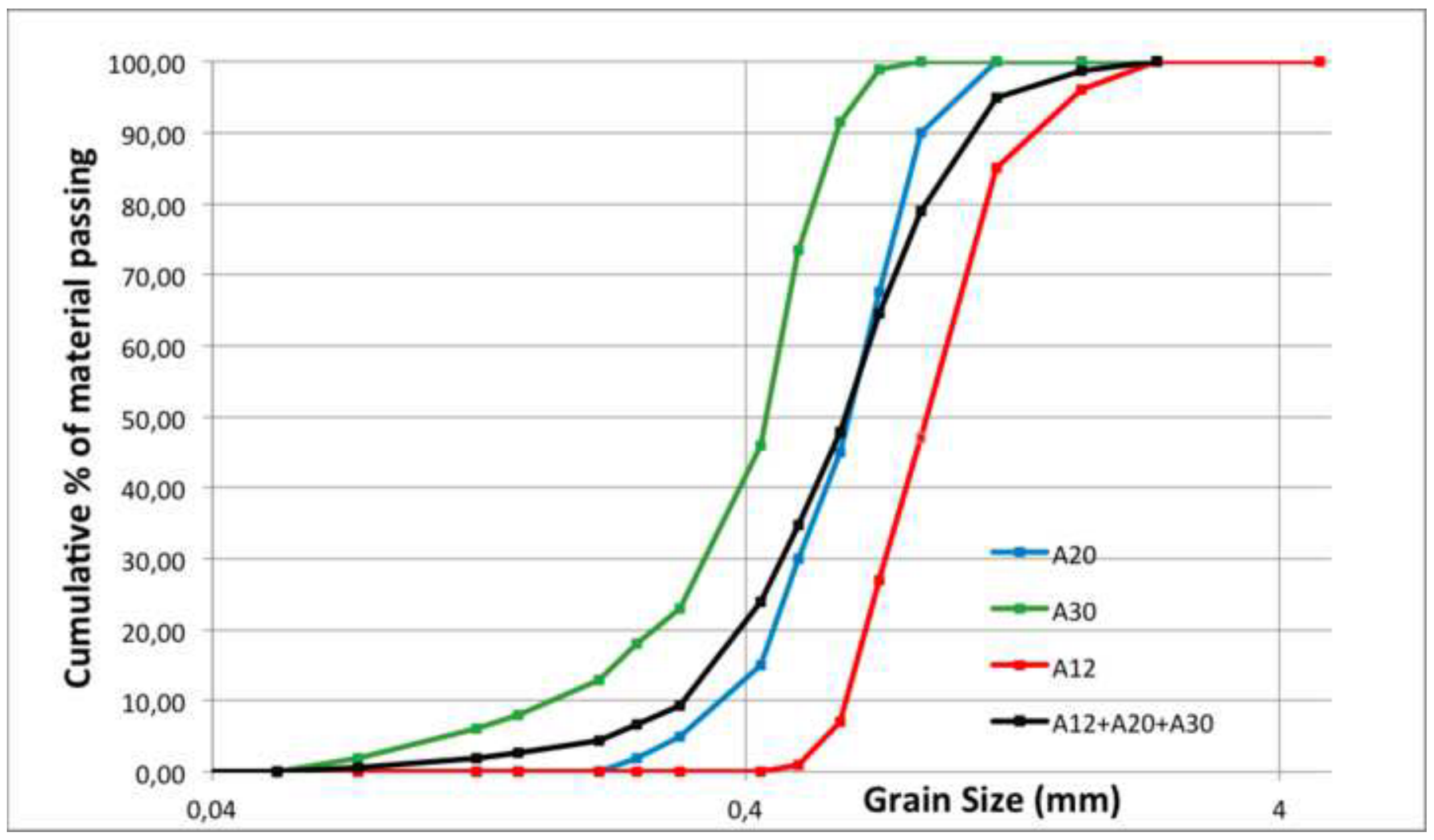




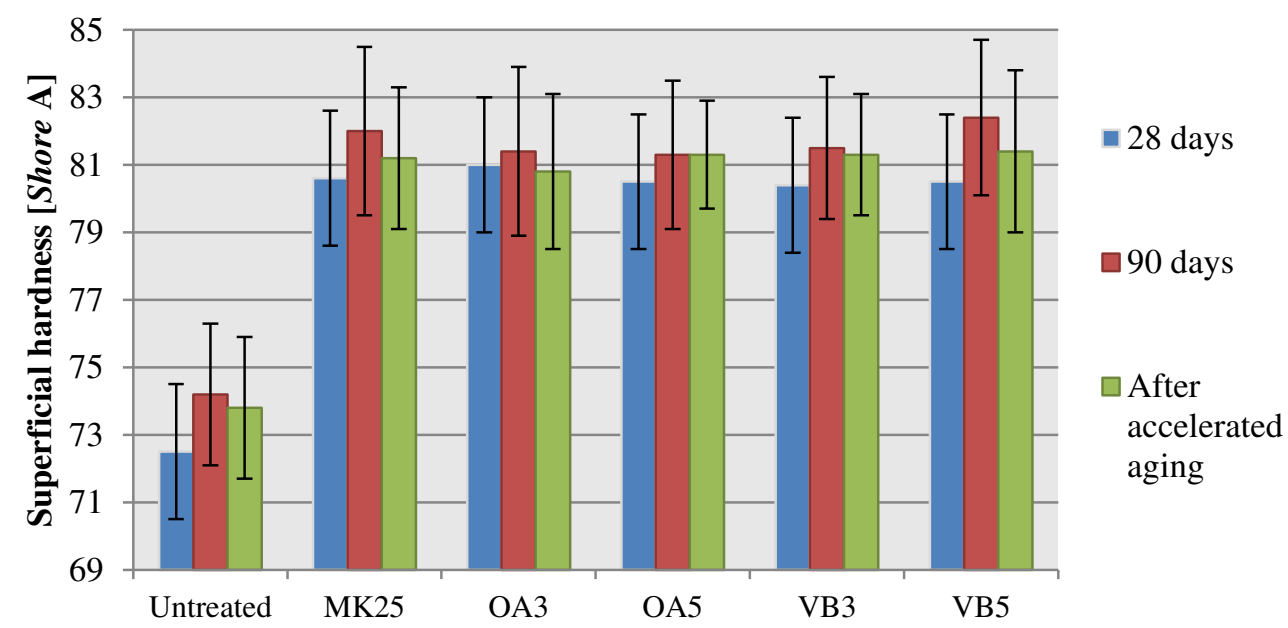

Fig.2: Superficial hardness results (average values and standard deviation) 


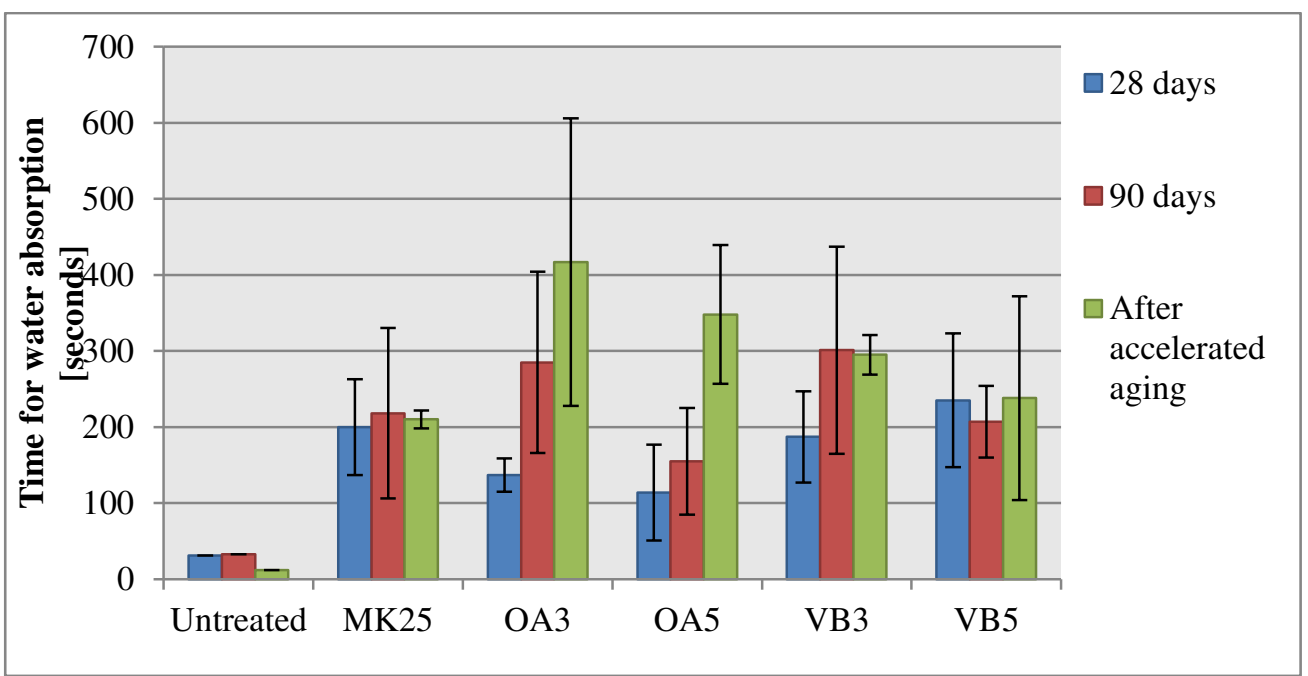

Fig. 3: Karsten tubes test results (average values and standard deviation). 


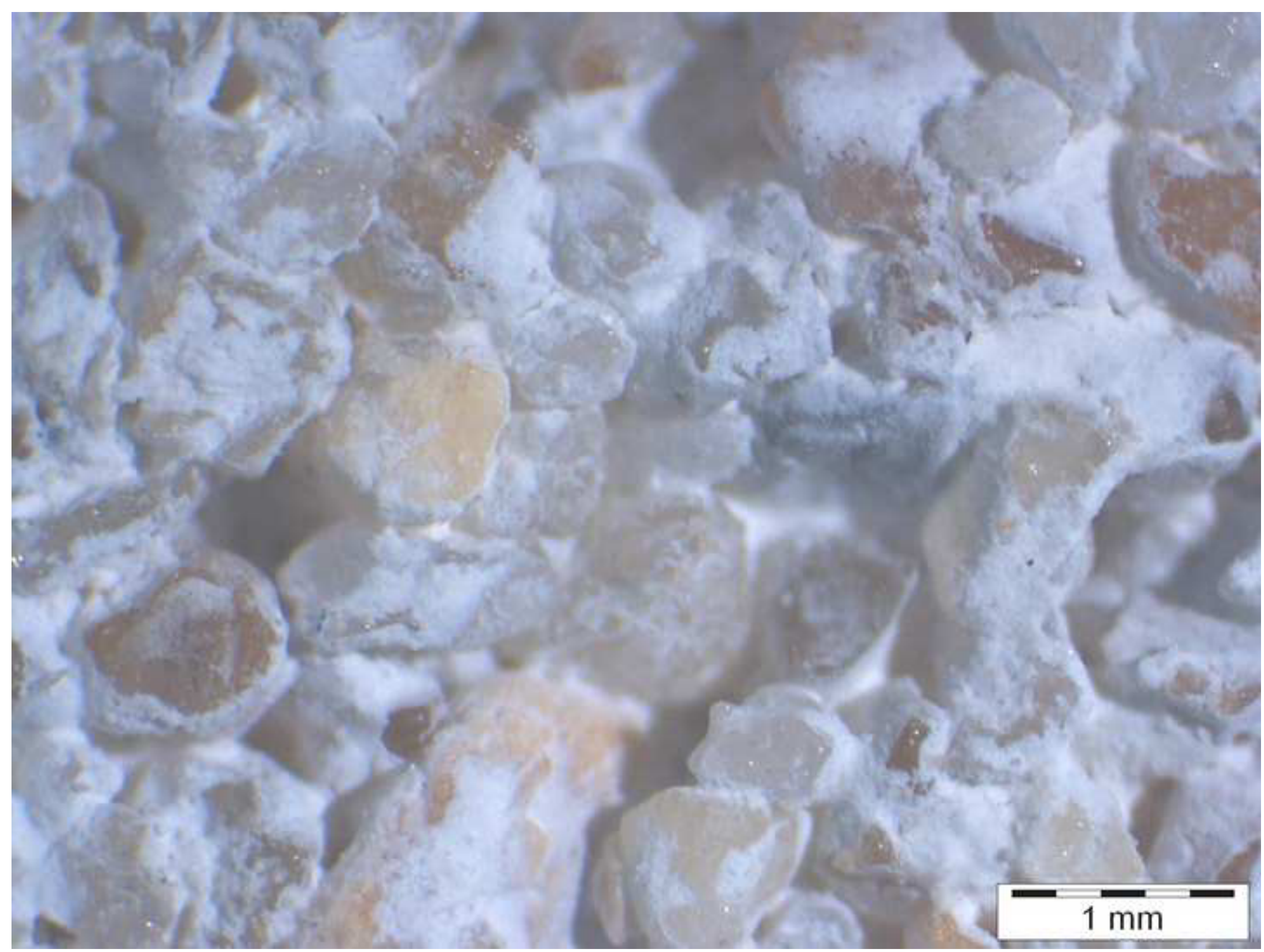


Click here to download high resolution image

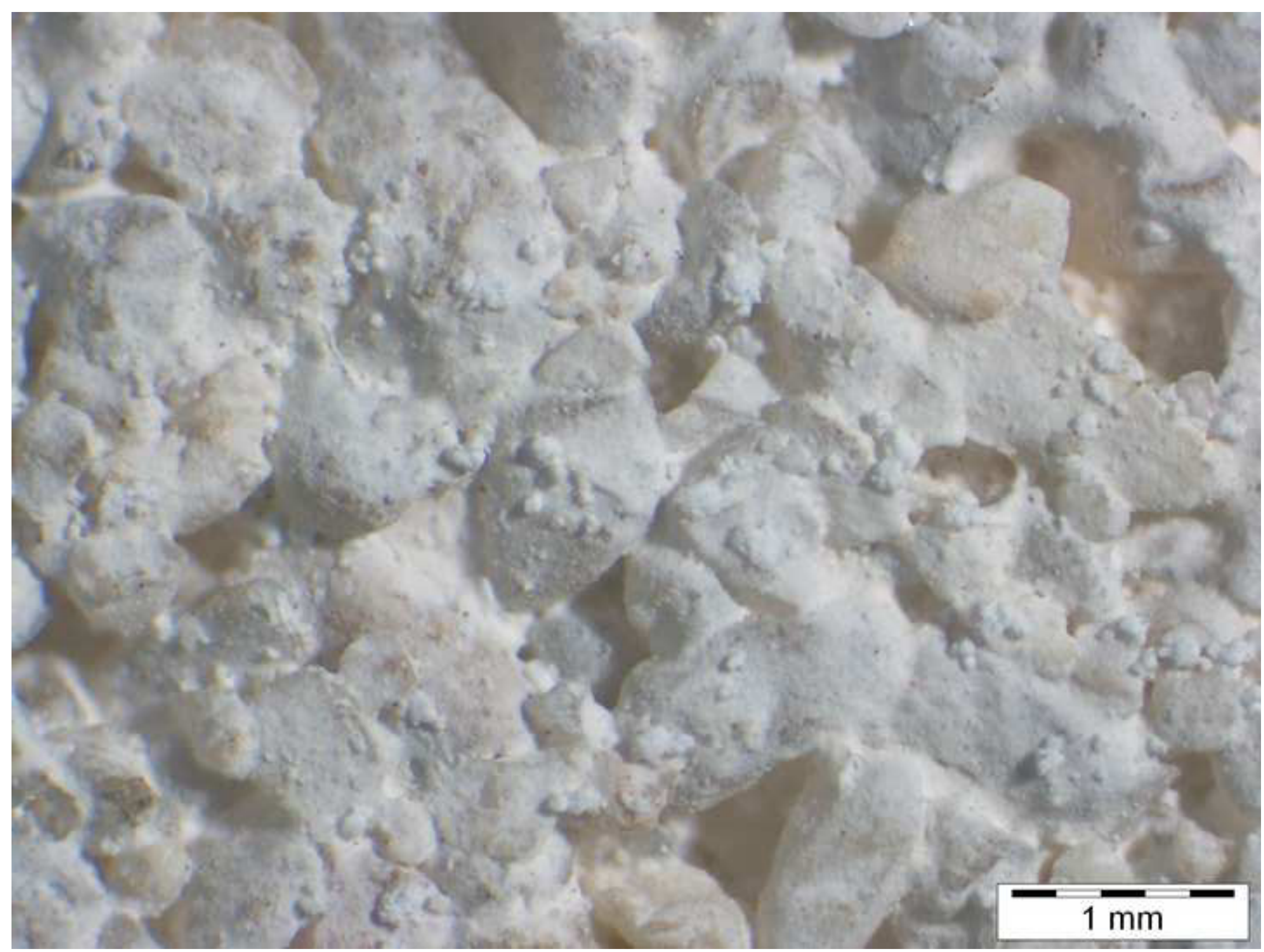


Click here to download high resolution image

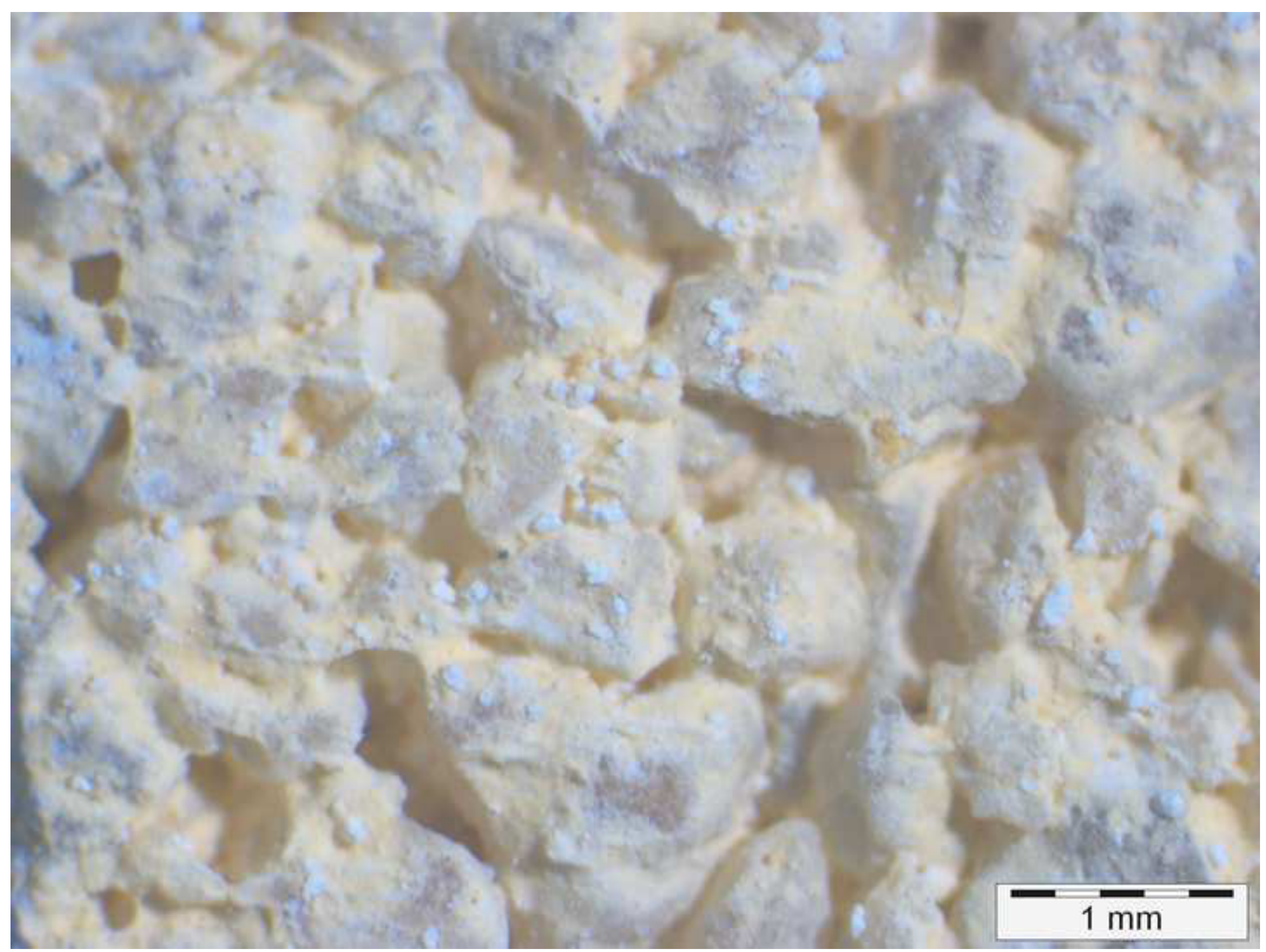


Click here to download high resolution image

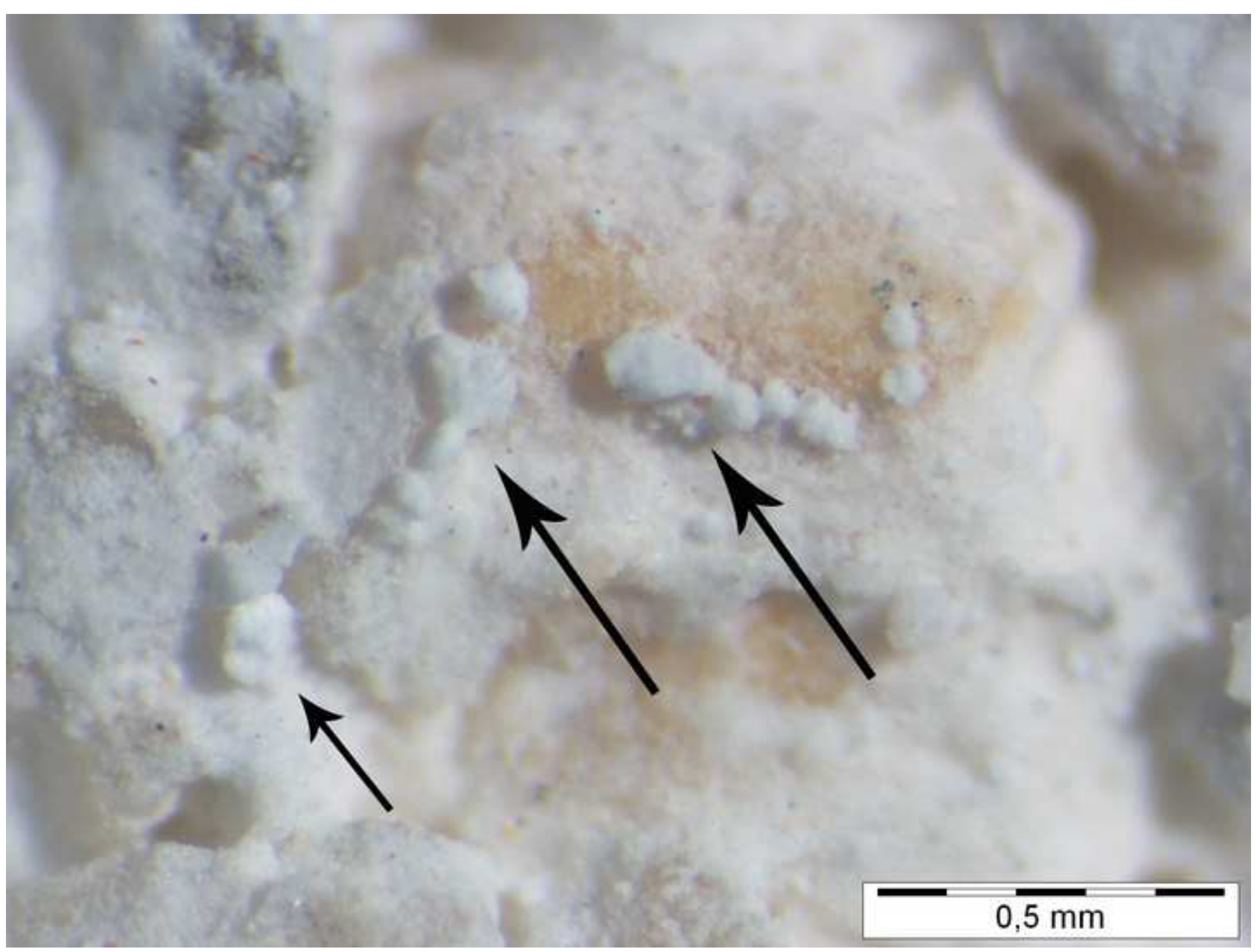




\section{$2,7 \mathrm{~mm}$}

\section{$5,1 \mathrm{~mm}$ \\ $2,3 \mathrm{~mm}$}

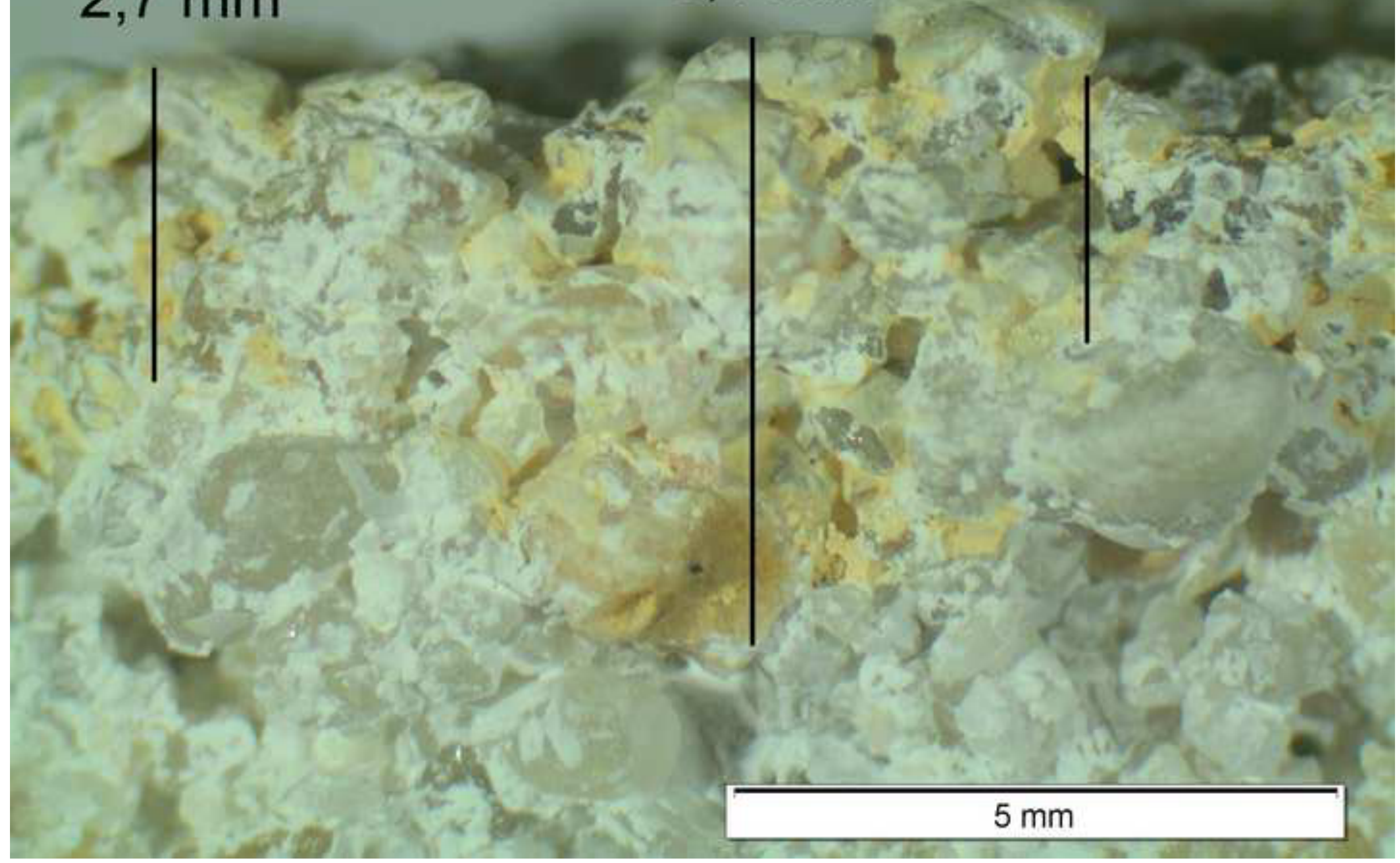




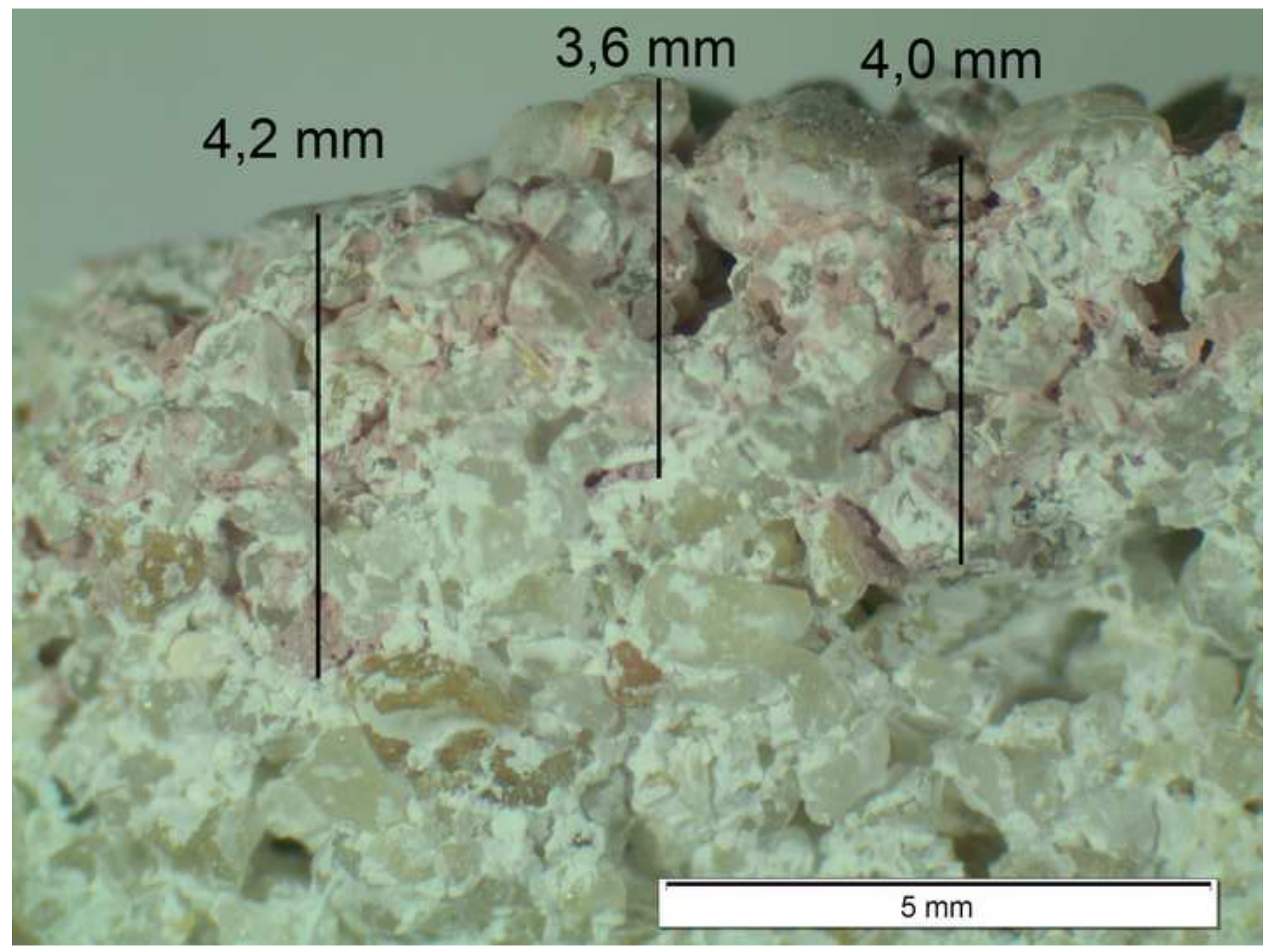

\section{$3,6 \mathrm{~mm} \quad 4,0 \mathrm{~mm}$}
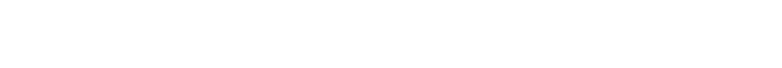

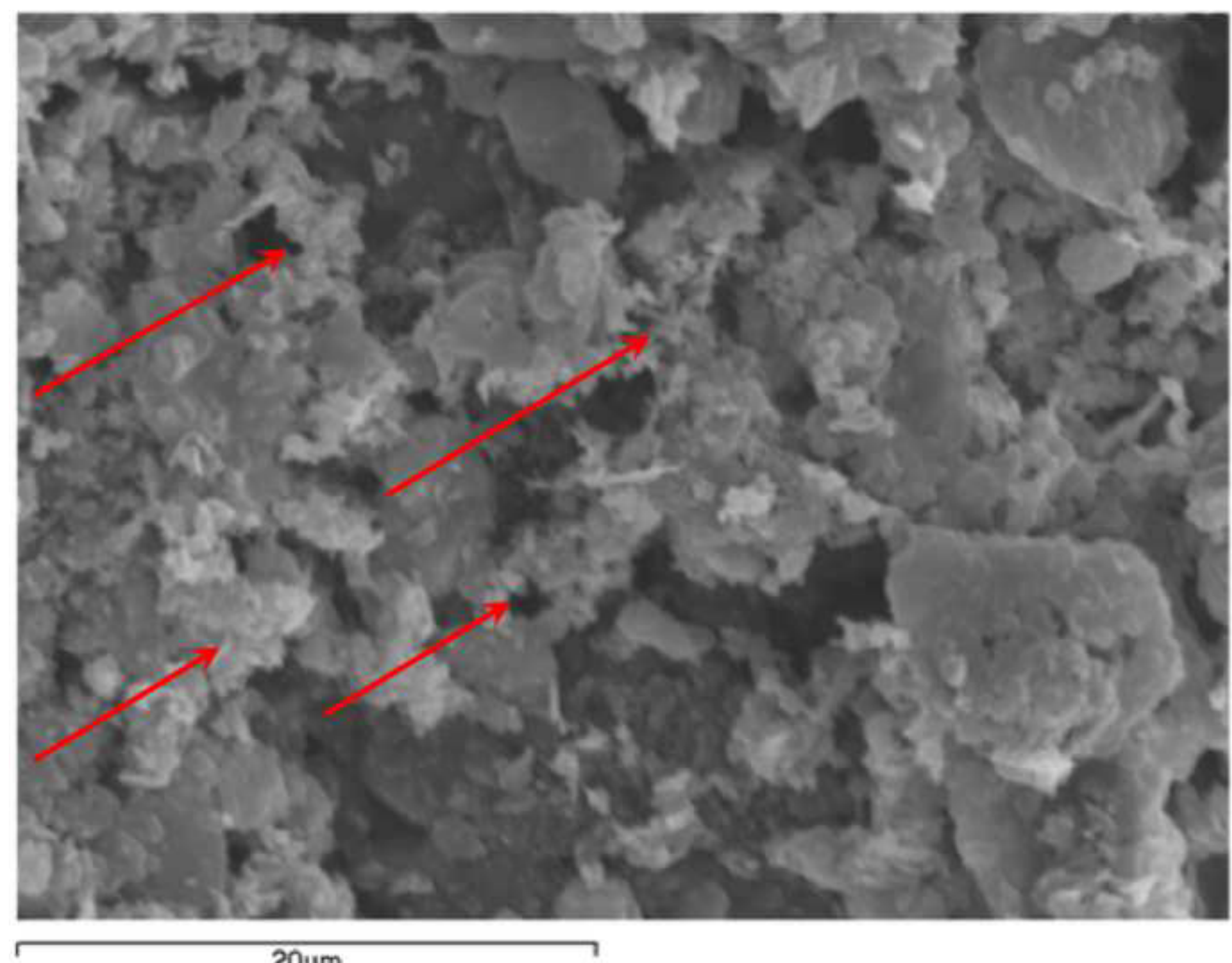

\section{$20 \mu \mathrm{m}$}




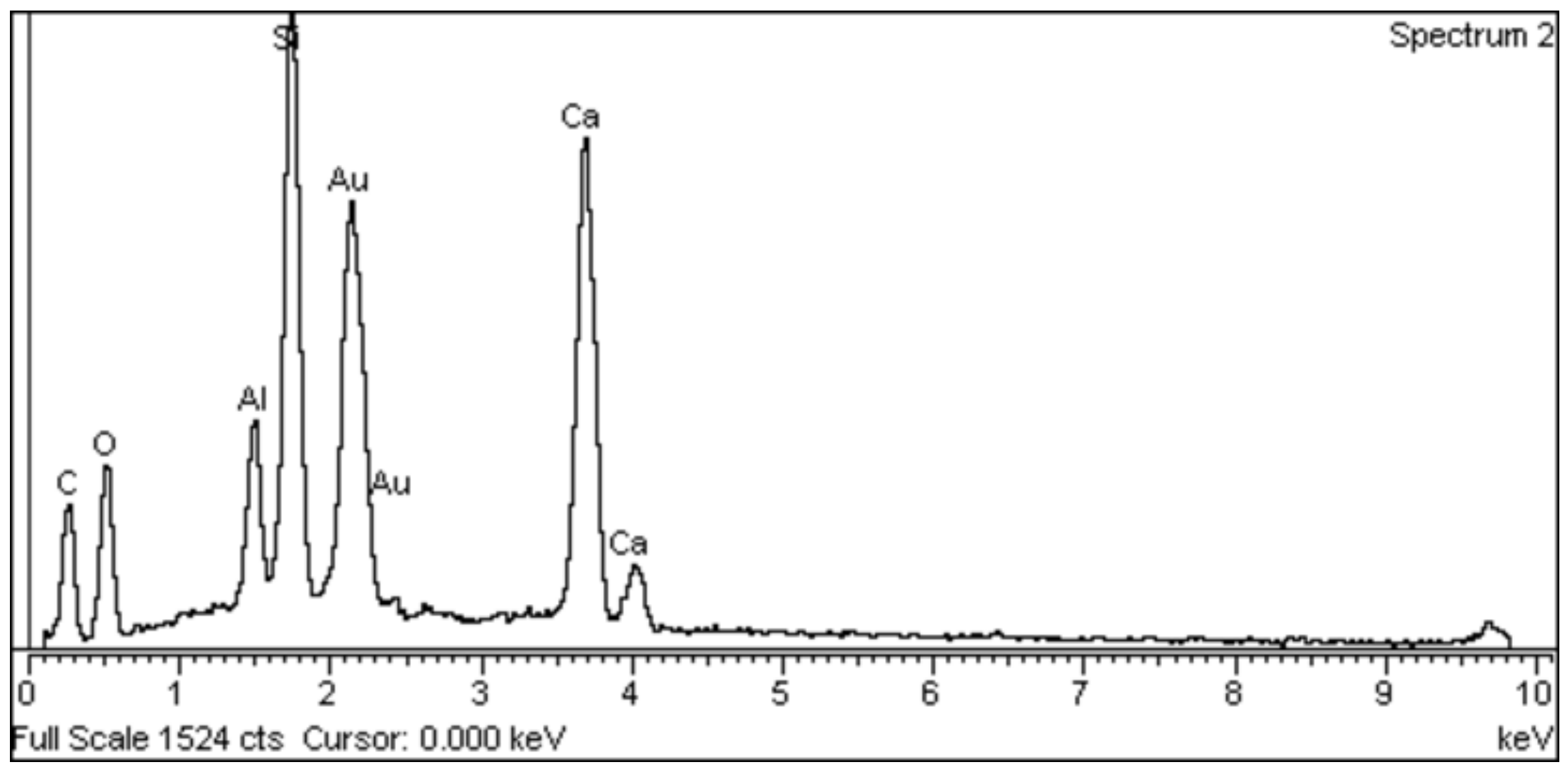




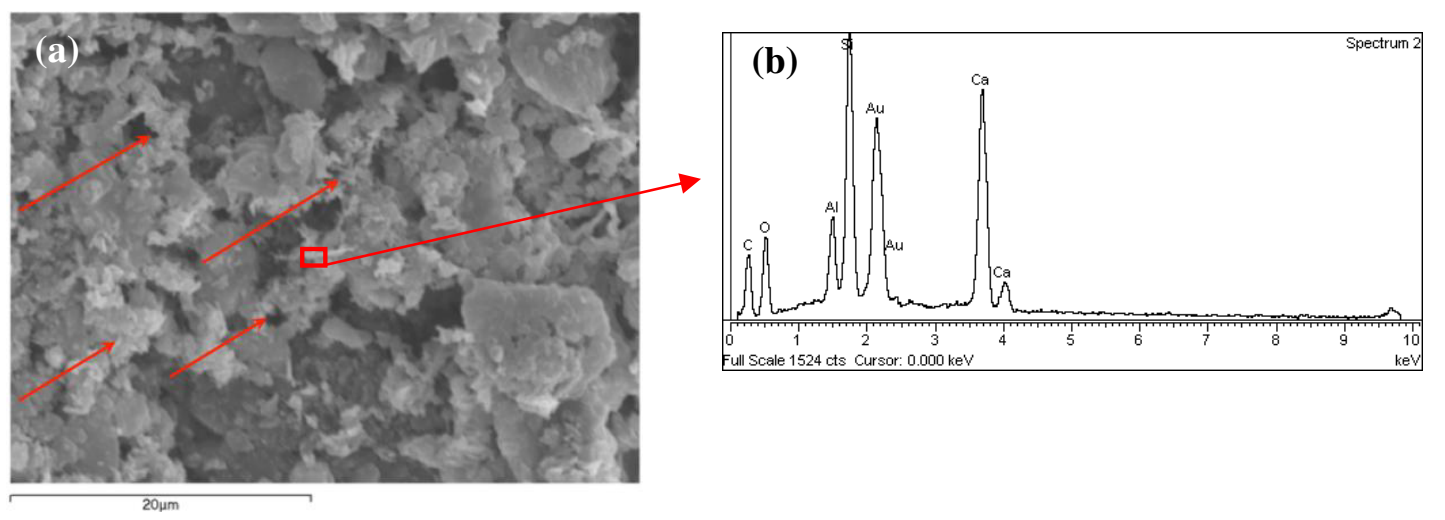

Fig. 6: SEM microphotographs of the specimen treated with MK25, where (a) arrows indicate pozzolanic products formations confirmed by (b) its corresponding EDS spectrum. 
Click here to download high resolution image

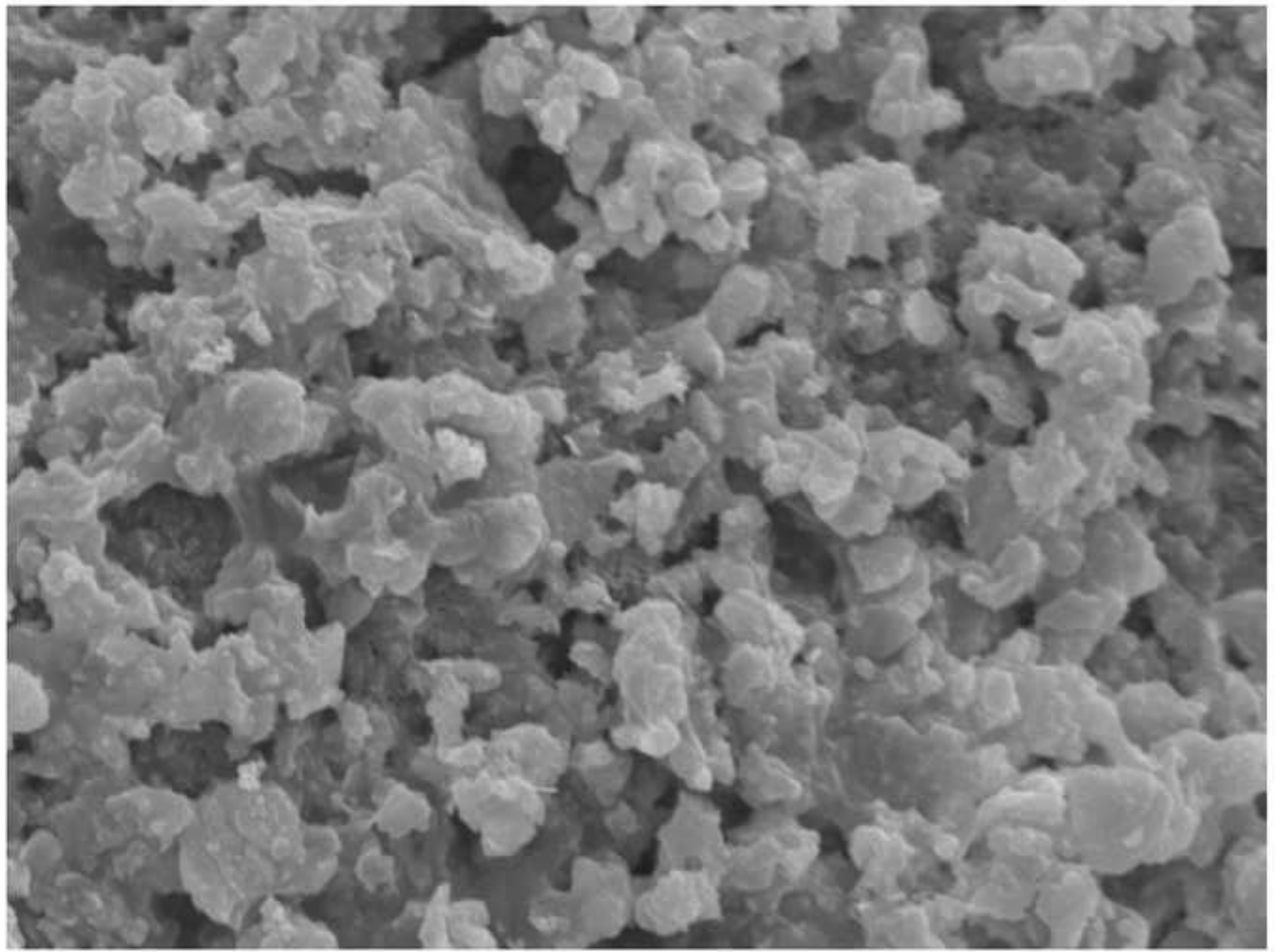

$20 \mu \mathrm{m}$ 


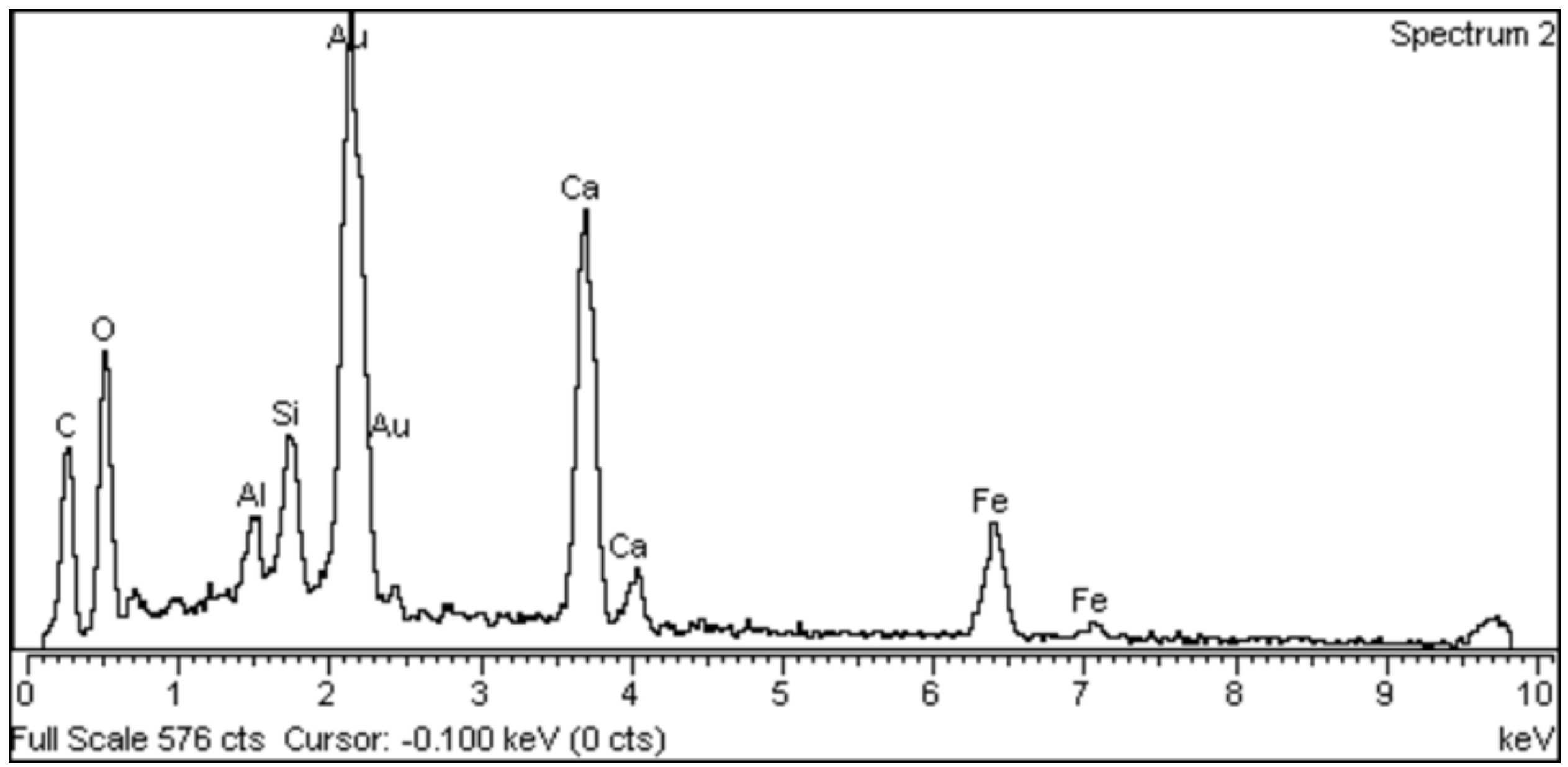




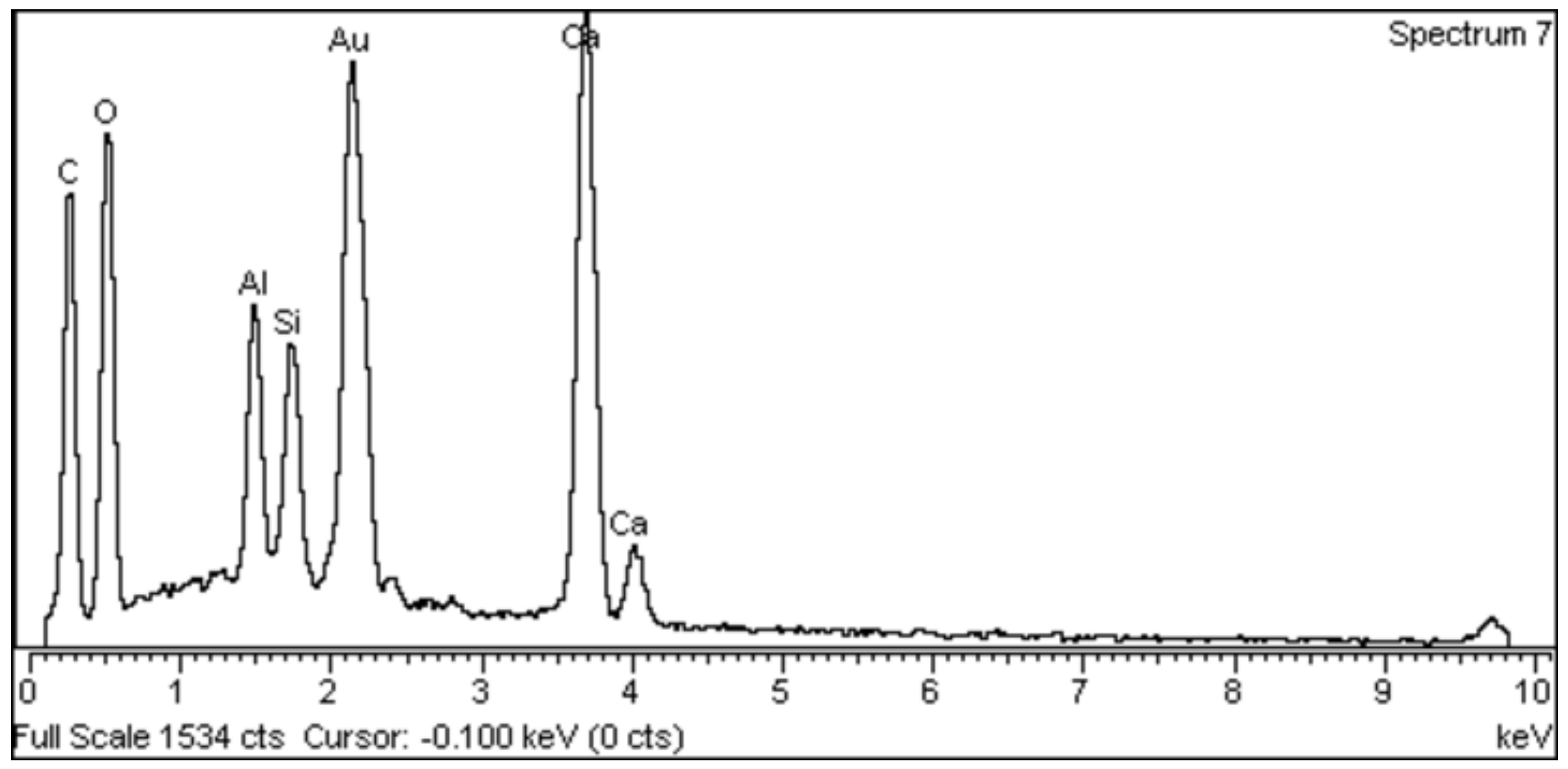



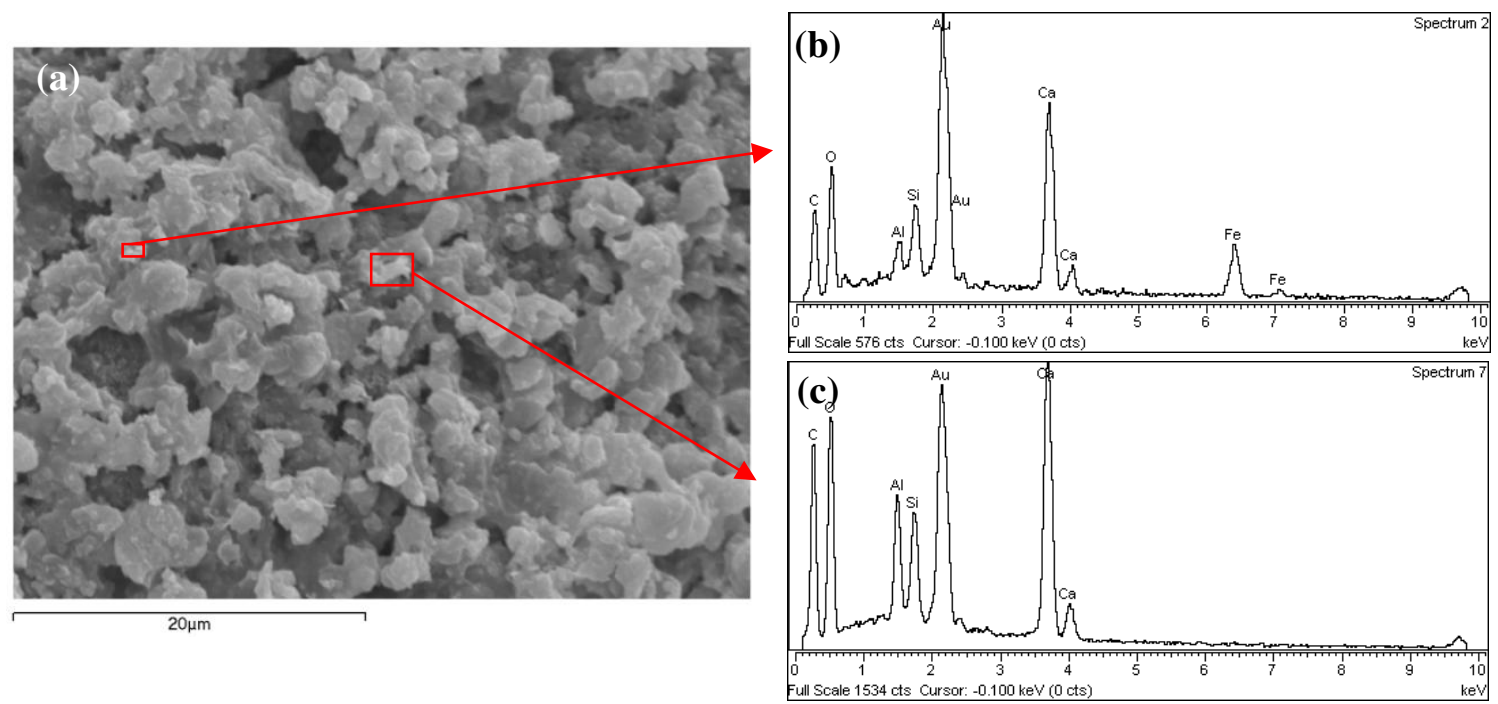

Fig. 7: (a) SEM microphotograph of the specimen treated with VB5; EDS analyses confirm that (b) the presence of hematite interferes in the formation of pozzolanic formations, (c) which are more abundant and developed when iron oxide are absent. 
Click here to download high resolution image

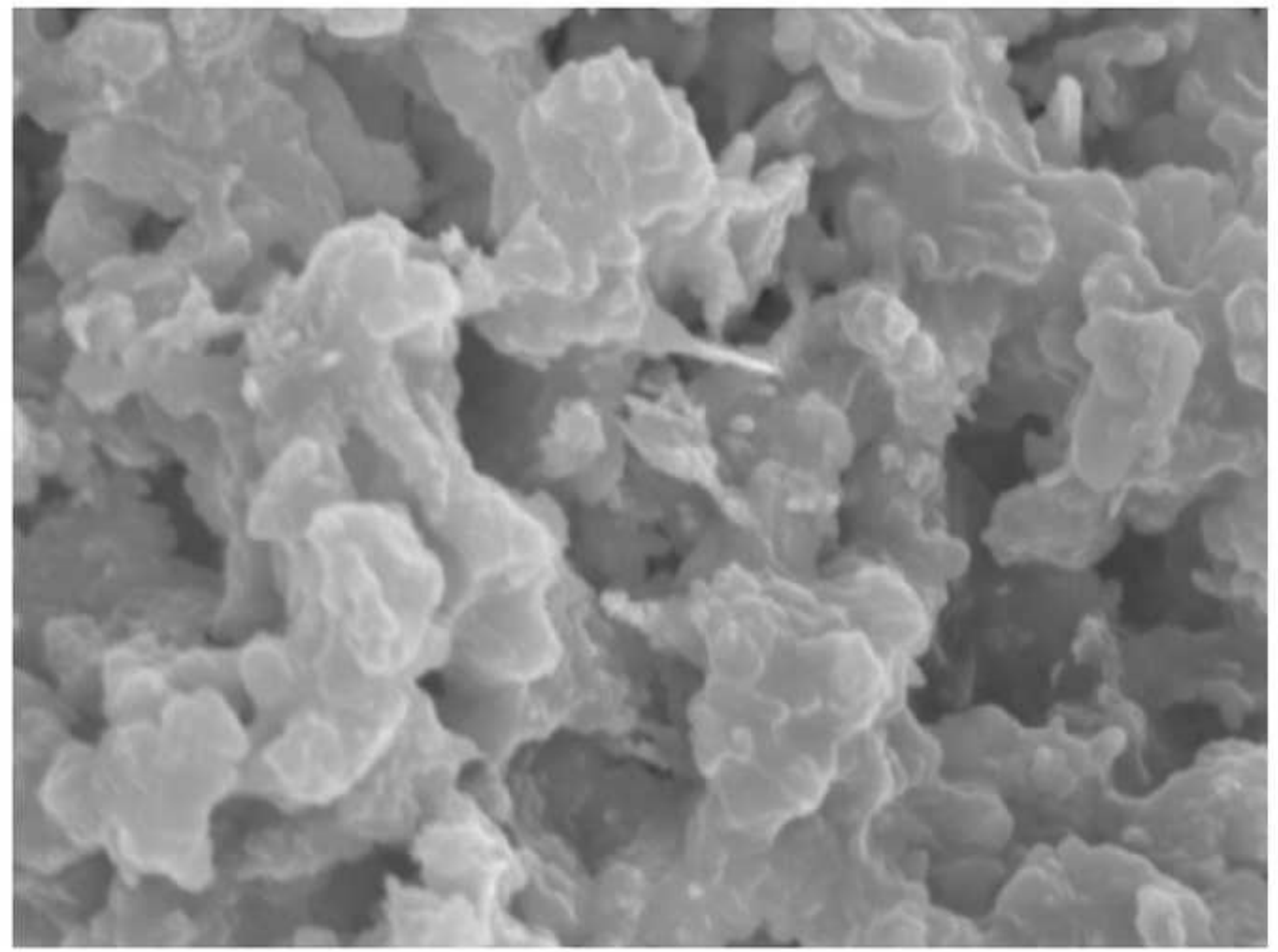

$8 \mu \mathrm{m}$
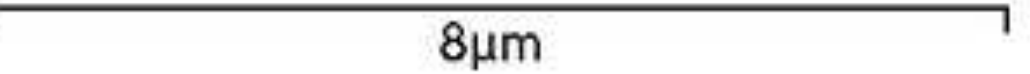


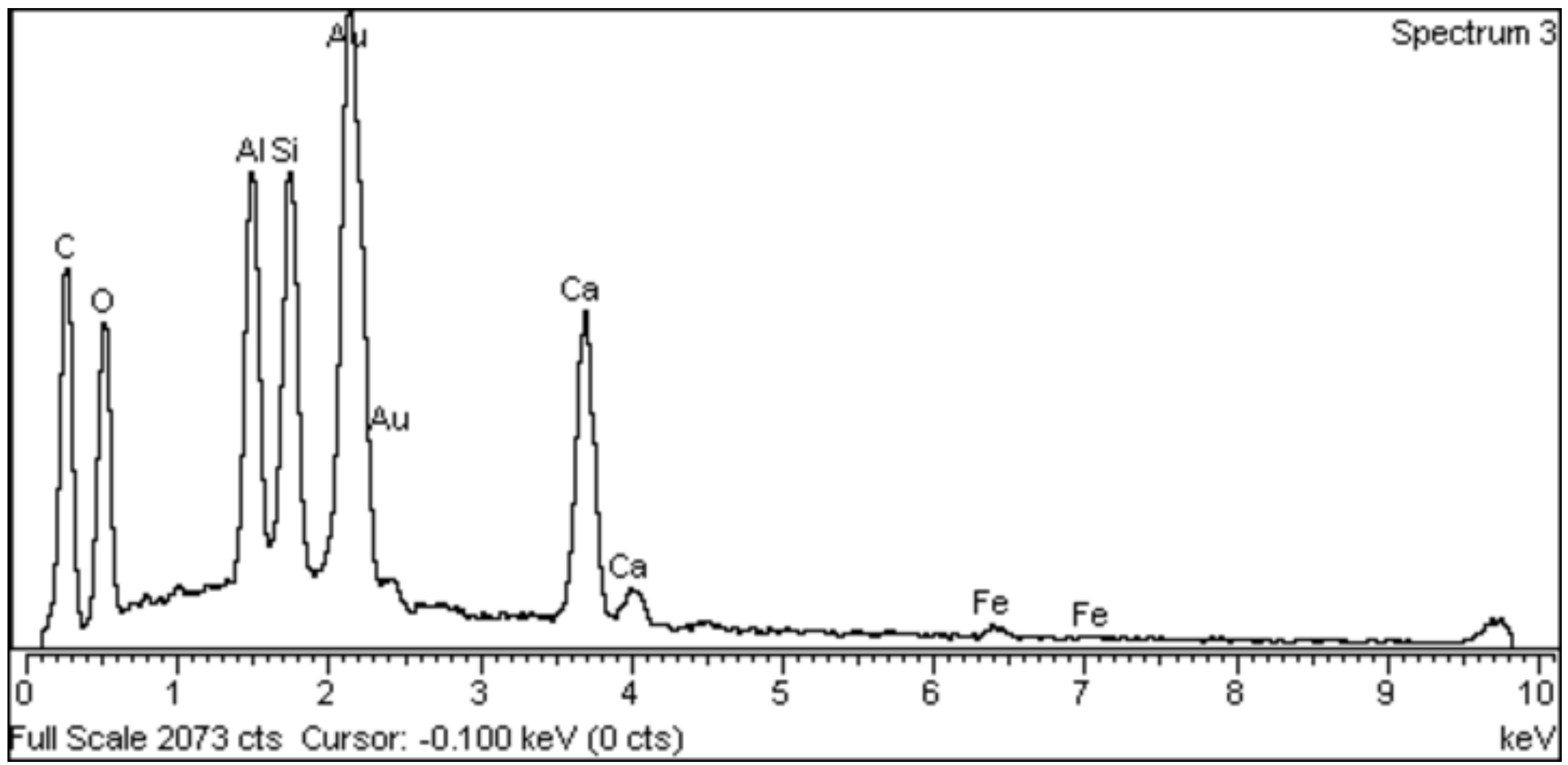




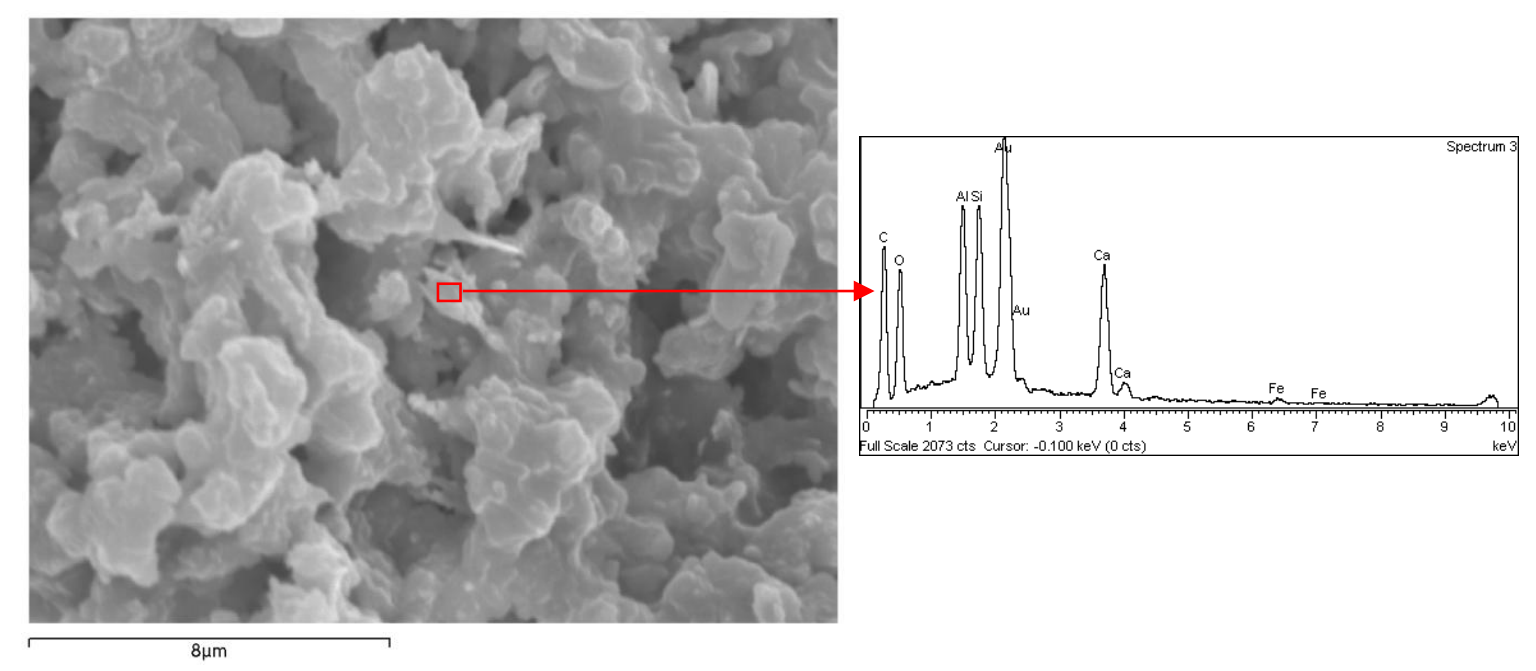

Fig. 8: (a) SEM microphotograph of the specimen treated with OA5; EDS analysis (b) confirm that the presence of goethite does not interfere in the formation of pozzolanic neoformations. 


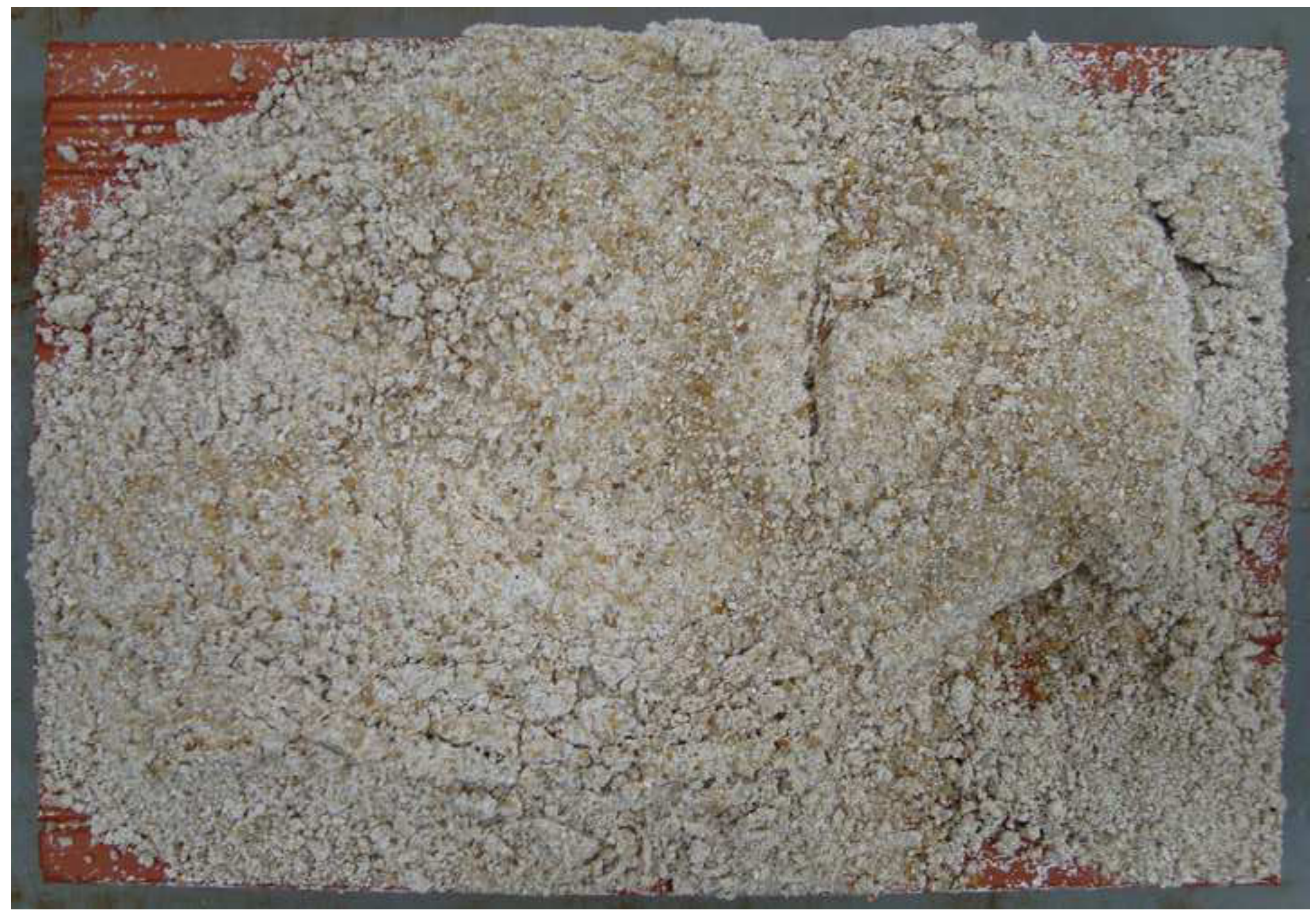



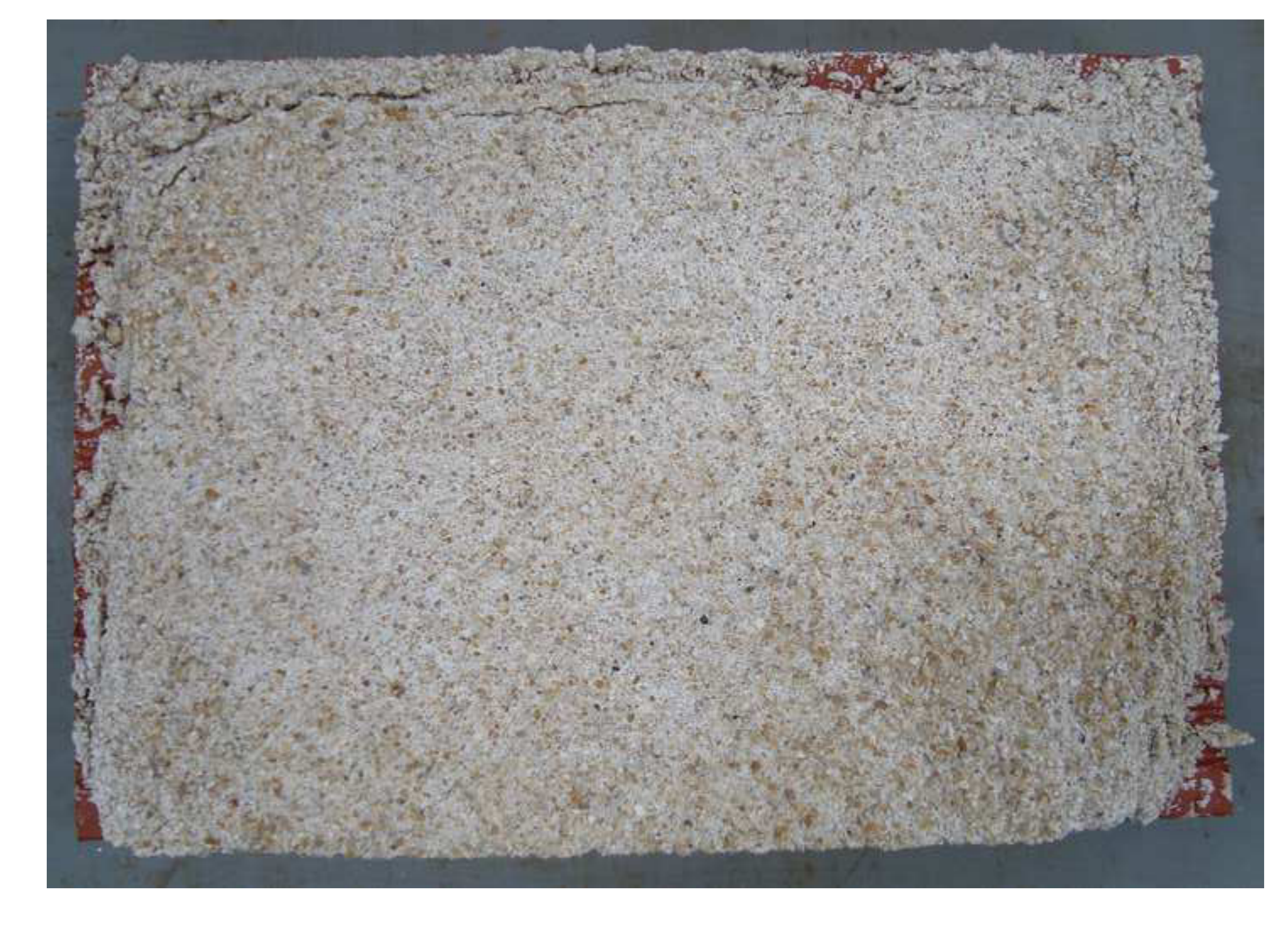

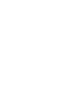
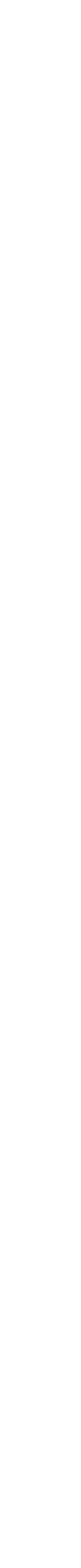


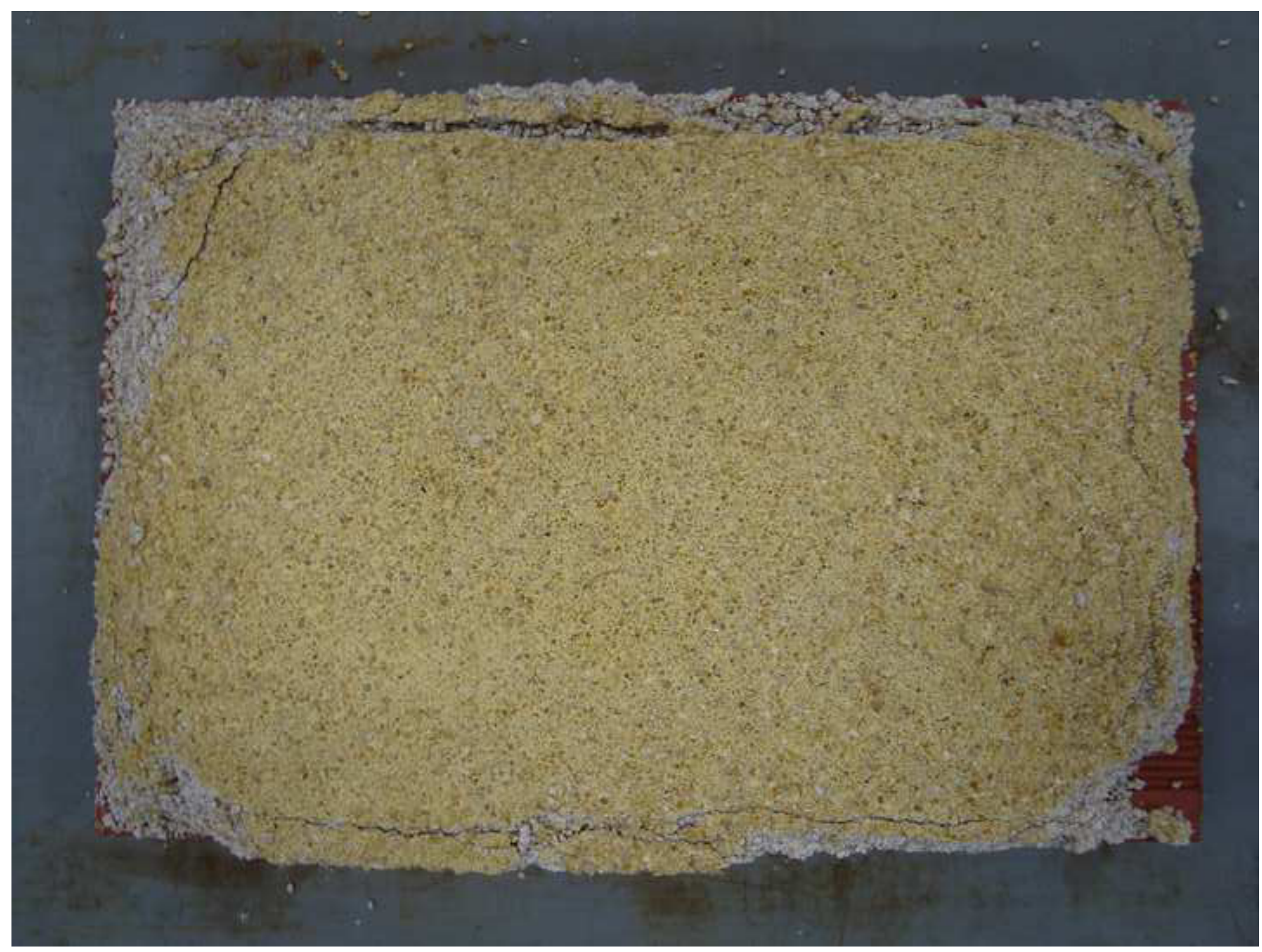




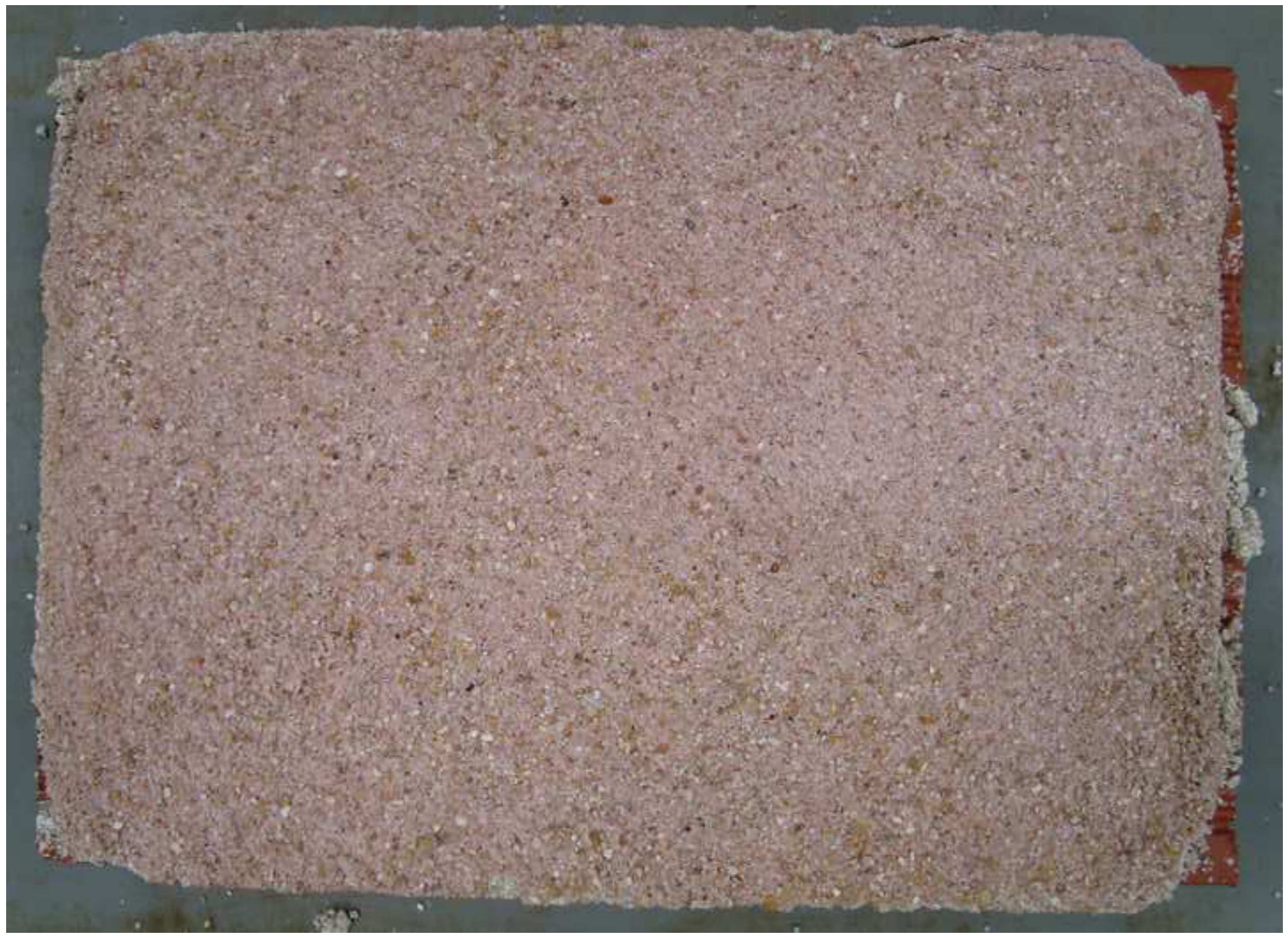

